\title{
Possible ecological advantages from use of carbonless magnesia refractory bricks in secondary steelmaking: a framework LCA perspective
}

\author{
F. Boenzi ${ }^{1}$ (D)
}

Received: 2 October 2020 / Revised: 26 May 2021 / Accepted: 12 July 2021 / Published online: 9 August 2021

(c) The Author(s) 2021

\begin{abstract}
In the present paper, two types of magnesia-based refractory bricks for the wear lining of a steel ladle furnace are considered, with the aim of comparing their ecological performances. The adopted methodology is the Life Cycle Assessment (LCA) approach from cradle-to-gate of the two brick product systems, in accordance with the European and International Standard EN ISO 14044:2006, and the chosen methodology for the Life Cycle Impact Assessment (LCIA) is ReCiPe 2016, considering the midpoint impact categories and the hierarchist perspective. The conducted study is part of a European industrial research project aimed at investigating the possibility of cleanliness improvement of the steel produced in secondary steelmaking, by reducing the refractory contamination in the steel ladle furnace. The compared refractory bricks consist of a reference, currently used, $\mathrm{MgO}-\mathrm{C}$ type and a more innovative "carbonless" one, containing magnesia and MA sintered spinel as principal components, on the basis of recipe data provided by the industrial partners of the project. The results attained so far in industrial practice are preliminary, because of the lack of a full-ladle lining experimentation, even though the application of the conceived innovative bricks in the upper part of the slag line of the ladle presents promising aspects. The results of the LCIA comparison between the two brick product systems highlight better performances for all the impact categories, except for "Human carcinogenic toxicity" and markedly for "Mineral resource scarcity." Besides these results, a general framework for shifting the ecological analysis to the steel production is provided. Calculations, referred to the production of one tonne of steel, are therefore performed, involving scenario assumptions not only regarding the refractory consumption but also the forecast operational features of the steel ladle with the "carbonless" lining. In this second set of results, it is clear how the principal contribution to almost all the impact categories is the electrical energy consumption of the ladle, while the contribution from the brick product systems remains important for the above-mentioned worsened impact categories, whose magnitude is strongly dependent on the refractory consumption.
\end{abstract}

Keywords Carbon-free refractories · Environmental impact · LCA · LCIA · ReCiPe $2016 \cdot$ Secondary steelmaking

\section{Introduction}

Refractory materials play a fundamental role in all the hightemperature industrial sectors, such as the production of glass, ceramics, cement and metals. According to Horckmans et al. (2019), the annual global production of

Editorial responsibility: Agnieszka Galuszka.

F. Boenzi

boenzi@poliba.it

1 DMMM (Dipartimento Di Meccanica, Matematica e Management) - Politecnico di Bari (Italy), Campus universitario, via Orabona 4, 70125 Bari, Italy refractories is around 35-40 million tonnes, with fluctuations largely dependent on the steel market demand, since the major share of around $70 \%$ is employed by the steel and iron industry, as also reported in other literature sources (Buhr et al. 2016; Muñoz et al. 2020; Odreitz 2016). Many types of refractory classifications exist, such as based on the method of installation (shaped or unshaped), on the type of bonding (ceramic or carbon bonded) and on the chemical composition (acid, basic, neutral), regarding the interaction of the main constituting raw materials with water (Buhr 1999; Fang et al. 1999; Horckmans et al. 2019). The present paper deals with refractories in the shaped form and in particular produced as bricks, to be installed in the working lining part of the refining ladle (ladle furnace, usually 
abbreviated as LF) for secondary treatments of steel. Secondary steelmaking or secondary metallurgy is defined as "any post-steelmaking process performed at a separate station prior to casting" and can be considered as the "perfect link between steelmaking and casting" (Dutta and Chokshi 2020). It is a very complex interdisciplinary topic (involving expertise in metallurgy, chemistry and production engineering) and in the modern steel-making process has the fundamental function of obtaining the desired properties characterizing the different grades of steel produced at industrial scale. It is carried out by means of a series of indispensable processes like desulfurization, deoxidation, decarburization, degassing, alloying, re-heating, homogenization of the molten metal (Ghosh and Chatterjee 2008) and in particular aimed at improving the steel "cleanliness" (i.e., lowering the inclusion contents). Some of these processes are performed in the same station and/or in subsequent separate processing steps, commonly referred to by means of their abbreviations. Examples of such stations are: the LF (Ladle Furnace), the VAD unit (Vacuum Arc Degasser), the CAS-OB unit (Composition Adjustments by Sealed argon bubbling and Oxygen Blowing), the RH-OB unit (Ruhrstahl Heraeus process and Oxygen Blowing), etc. The primary functions of the LF are the very strict control of the chemical composition of the molten steel (by the addition of micro-alloying elements in proper sequence to maximize the recovery) and of its temperature (by electric arc heating, with graphite electrodes), the very deep level of desulfurization, the homogenization of the melt through inert gas stirring (i.e., argon purging from the bottom), while secondary functions can be the cored wire addition for changing the morphology of inclusions, the separation of inclusions for high cleanliness, the de-gassing (removal of gases like hydrogen and nitrogen), the de-phosphorization (Dutta and Chokshi 2020). The refractory materials used in the LF have to withstand very high operating temperature ranges and possess high wear resistance; typically, basic or neutral lining (doloma, alumina) is employed in steel contact areas and more expensive, high corrosion-resistant refractories (magnesia-graphite) at the slag line (Horckmans et al. 2019; Smith et al. 1999). In general, the requirements of the LF refractory lining can be summarized in the following (Ghosh and Chatterjee 2008): stability and inertness to the liquid steel, to avoid the introduction of undesirable impurities; low thermal conductivity to prevent heat losses and, in contrast, a satisfactory thermal shock resistance (a trade-off must be attained); limitation as low as possible of erosion (which introduces non-metallic inclusions and impair the steel "cleanliness") and of corrosion, which causes a change in the composition of steel, like increasing its oxygen content. In industrial practice, the lining of the ladles is made up of different layers ("composite lining," according to Ghosh and Chatterjee 2008): the sidewall, constituting the working (or wear) lining, in contact with the molten steel and the slag (differences in the refractory composition are normally adopted, as stated above) and an inner layer constituting the "permanent" lining, generally composed of a safety layer and an insulation layer in contact with the ladle steel shell (examples of such layer configurations can be found in Buhr et al. 2016; Santos 2018; Santos et al. 2020). Currently, $\mathrm{MgO}-\mathrm{C}$ bricks for the wear lining (based on magnesia as the principal component, added with carbon in the range 10-15\% as illustrated in Buhr et al. 2016 and in Horckmans et al. 2019) can be considered among the most performing refractory bricks used in industrial practice, with "no equivalent commercial refractory to overcome the corrosion performance at the slag line" (Santos et al. 2020). In recent years, under the thrust of ever increasing international competition in the steel sector, industrial and academic research has focused particular attention on the improvement of the quality of high-purity steel grades, seeking to comply at best with very stringent specifications for undesired impurities and alloying elements (Buhr et al. 2016). A determinant role for attaining the desired quality targets in steelmaking is played properly by the secondary metallurgy processes and by the LF in particular, which can be viewed as a "metallurgical reactor," according to Buhr et al. (2016), also on the basis of the complex interaction mechanisms between the steel liquid phase and the refractory material in contact with it, as highlighted in Buhr (1999), in Buhr et al. (2016) and in Cappel (2007). In this context, the control of any form of impurity in the steel matrix is determinant. Harmful impurities in steel include sulfur, phosphorus, oxygen, nitrogen and hydrogen, with the latter three elements known as interstitials since they occupy interstitial sites in the iron lattice, determining loss of ductility, lower impact strength and poorer corrosion resistance (Ghosh and Chatterjee 2008). Oxygen and sulfur are also the constituents of non-metallic particles (oxides and sulfides), known as inclusions, in single or combined form, and other types of inclusions can be present as nitrides and phosphides (Dutta and Chokshi 2020; Ghosh and Chatterjee 2008). Machinability is favored by certain interstitial inclusions, but, in general terms, inclusions are undesirable and should be removed to as low levels as possible because detrimental to the serviceability of the steel. Inclusions avoidance and separation techniques are industrially common practice; aside these techniques, inclusion shape control and modification can also be implemented (Buhr et al. 2016; Cappel 2007), specifically in the LF, in order to improve the steel cleanliness. Carbon is also present in interstitial form in the iron lattice as well as in the form of cementite $\left(\mathrm{Fe}_{3} \mathrm{C}\right)$ and, unlike the other interstitials, being always required in steel, is an essential part of the steel specifications. However, recently, the specifications of special sophisticated steel grades, known as "Interstitial Free" (IF) steels or Ultra-Low Carbon (ULC) steels, lay down very low content limits for 
nitrogen and carbon alike, even lower than $30 \mathrm{ppm}$ (Dutta and Chokshi 2020; Ghosh and Chatterjee 2008). The interest of the European Community in funding this field of research is testified for example by the research project illustrated in Pissenberger et al. (2009) and aimed at the optimization and evaluation of different production routes to achieve highquality strip for ULC/IF steel grades. Also the pick-up of the carbon from the refractory material must be taken into account, being the refractory lining of steel ladles a possible source of contamination if the refractory material contains carbon, especially in form of graphite (Buhr et al. 2016), as in the case of $\mathrm{MgO}-\mathrm{C}$ bricks. In the context of European research funded for improving the cleanliness of ULC steels, the project "LeanStory" ("Improvement of steel cleanness by reducing refractory contamination in secondary steelmaking") lays down, with the aim of finding, for the said motivations, feasible alternatives to the $\mathrm{MgO}-\mathrm{C}$ bricks wear lining currently employed and also seeking possible benefits under the ecological point of view and better health conditions in the work environment (by the prevention of emission of hazardous substances like PAHs and phenols, as illustrated in the following). In the course of this research project, many recipes of "carbonless" refractory bricks were developed, all of which based on $\mathrm{MgO}$ as the principal component. The results attained so far in industrial practice are preliminary, because of the lack of a full-ladle lining experimentation with the lastly formulated bricks, even though the experimentation, limited to the upper part of the slag line, presents promising aspects. Nevertheless, some realistic hypotheses have been deployed, in particular regarding the forecast operational performances of the new carbonless ladle lining and a Life Cycle Analysis comparison has been carried out. A literature survey regarding LCA studies of bricks in general (not restricted to the specific field of refractory applications and regarding both traditional and innovative types) can be found in Huarachi et al. (2020), highlighting, in particular, the need of deeper studies on the recycling and re-using possibilities of alternative bricks and on finding alternative binders, in order to limit the very impacting phase of firing during manufacturing, or on the use of less impacting fuels sources (renewable) if firing cannot be avoided. In An et al. (2018), a wide overview of magnesia refractory products and of their production processes is provided; then, a scenario LCA is carried out, focused on carbon emissions (direct and indirect) only, comparing several magnesia-based products in four scenarios. Emphasis is put on the important reduction which $\mathrm{CO}_{2}$ capture and storage (CCS) technologies can attain in the production phase and on the importance of the service lifetime in the use phase, introducing the definition of "carbon emission rate," in particular with reference to the working lining of LFs with two types of MgO-C bricks (fused magnesia in different crystalline forms). From the analysis of existing literature, however, a general framework by which the differences arising from the use of two different refractory bricks for the wear lining of a LF (with associated diverse ecological impacts) can be reversed on the production of the final product, which is steel, seems missing and the present paper aims at filling this gap. The attention is focused on the wear lining only of the LF, which is periodically demolished and rebuilt after a quite variable number of heats, as illustrated in the following; furthermore, for simplification reasons, a fundamental assumption of the following LCA is the homogeneity of the used refractory material (i.e., the same high-performance material is employed for both the slag line area and other zones of the sidewall). The paper is organized as follows: in "Materials and methods Section" the boundaries of the applied LCA methodology are illustrated, alongside the compared refractory brick product systems (deriving from their recipes) and the theoretical basis for shifting the results of the LCIA (Life Cycle Impact Assessment) analysis to the steel production are laid down, taking into account also the operational features of the ladle. In "Results and discussion Section" the results of the adopted LCIA methodology (ReCiPe 2016) are shown and discussed, considering, as the functional unit of the analysis, one tonne of steel produced (comparative results concerning the two brick product systems can be found in "Supplementary Appendix"). For this purpose, the operational data of the ladle furnace in the current situation (adopting the traditional $\mathrm{MgO}-\mathrm{C}$ bricks lining) and the forecast data with the "carbonless" lining are also illustrated. Finally, in "Conclusion Section," further indications related to the results are drawn and conclusive remarks, including future directions of the work, are provided. The project "LeanStory" has been carried out in the period 2015-2019, with experimental and industrial setup in Sweden and Spain.

\section{Materials and methods}

The comparative analysis conducted in the course of the funded research project has required two inter-linked steps: in the first, two LCAs from cradle-to-gate have been led with reference to the types of bricks (traditional, currently used, and new "carbonless" type), therefore considering as the functional unit of the analysis one tonne of refractory bricks to be installed in the steel ladle. The underlying fundamental hypothesis of the analysis carried out is the complete substitutability of the two materials for the same function performed or, at least, the substitutability at a great extent of the refractory mass, except for restricted critical parts of the ladle, which are excluded from the present analysis. This first step, specifically requested by the project partners in order to compare the ecological performances of the brick product systems themselves, is propaedeutic for the second, and the results are illustrated synthetically in 
Table 1 Emissions for a novolac-type phenolic resin at $1000{ }^{\circ} \mathrm{C}$ as mol\% (data from Irie and Rappolt 2010), as weight\% composition and as mass referred to one tonne of the reference $\mathrm{MgO}-\mathrm{C}$ refractory

\begin{tabular}{lllllccccc}
\hline Substance & Water & $\mathrm{CO}$ & $\mathrm{CO}_{2}$ & $\mathrm{CH}_{4}$ & Phenol & Xylenol & Benzene & Toluene & $\mathrm{H}_{2}$ \\
\hline mol \% (at $1000{ }^{\circ} \mathrm{C}$ ) & 23.4 & 5.5 & 1.6 & 10.0 & 7.1 & 1.8 & 0.2 & 0.3 & 50.1 \\
Molecular weight [g/mol] & 18.0153 & 28.0101 & 44.0095 & 16.0425 & 94.1112 & 122.1600 & 78.1118 & 92.1384 & 2.0159 \\
Weight \% & 22.93 & 8.38 & 3.83 & 8.72 & 36.34 & 11.96 & 0.85 & 1.50 & 5.49 \\
Mass [kg] & 5.73 & 2.095 & 0.957 & 2.18 & 9.085 & 2.99 & 0.2124 & 0.376 & 1.373 \\
\hline
\end{tabular}

bricks (assumed the volatile fraction as $50 \%$ of the total input mass of $50 \mathrm{~kg}$, according to the recipe)
"Supplementary Appendix." In the second step, a change of the functional unit is operated, shifting the comparison to the production of the final product, that is one tonne of steel; consequently, a transposition of the impacts arising from the different refractory brick lining is operated. The general framework of the analysis requires the modeling of the product systems of the refractory brick production, including all the suppliers involved, the acquisition of raw materials, their production routes and the transports, as prescribed in the international and European technical standard EN ISO 14044 (CEN 2006). In the next section, an overview of the different recipes of the traditional $\mathrm{MgO}-\mathrm{C}$ bricks and of the new "carbonless" ones is provided, along with a brief description of the supply chain of the second type of bricks, since the product system of the reference $\mathrm{MgO}-\mathrm{C}$ bricks is illustrated and can be found in Boenzi et al. (2019). All the transport distances from the sites of the several suppliers of the bricks' raw materials are quantified taking into consideration the localization of the brick manufacturing plant in Northern Spain (Asturias region). The calculation software of the analysis is OpenLCA version 1.7.4 (openLCA 2021), implementing the ecoinvent database version 3.4 (The ecoinvent Database 2017) in the form of the "Allocation, cut-off by classification" system model. The used data records (with their proper Life Cycle Inventories, LCIs) in that database for the upstream processes and for the energy providers (i.e., gas, electricity, etc.) and transports providers (i.e., lorry and ship) are also illustrated in the following section.

\section{Recipes description with LCls and processes of their components}

The currently used traditional $\mathrm{MgO}-\mathrm{C}$ bricks for the ladle lining are "carbon bonded" or "tempered" bricks (as opposed to "ceramic bonded" as illustrated in Horckmans et al. 2019), in which phenolic resin is the binder component. In Boenzi et al. (2019) (p. 7 - Table 3), for the reference $\mathrm{MgO}-\mathrm{C}$ bricks an adjustment of the recipe weight percentages was adopted, so that the input mass was equal to the solid mass fraction only of the bricks, resulting from subsequent ladle heats, after the hypothesized weight loss (assumed coming from $50 \%$ of the total content of phenolic resin, as volatile fraction, on the basis of data reported in Funabiki et al. 1981).

In reality, the functional unit ( 1 tonne of bricks) at the manufacturer's gate should be referred to the mass of bricks shipped to the steel plant and installed in the ladle, since, at the brick manufacturing plant, just a very moderate heating occurs (consisting of a tempering process, as reported in Table 5), causing not appreciable weight losses till around $300{ }^{\circ} \mathrm{C}$, as reported in Ebner et al. (2017) and experimentally found in Moch et al. (2008) by means of a test equipment for dolomite resin-bonded bricks. Since the weight loss (hypothesized essentially due to the phenolic resin degradation) can be assumed entirely occurring after the installation (during the ladle pre-heating phase and frequently also at the first heats of operation as reported in Ebner et al. 2017), no recipe adjustment is necessary and the total mass of aerial emissions can be assumed $25 \mathrm{~kg}$ for 1 tonne of bricks $(2.5 \%$ of $5 \%$, on the basis of the weight composition reference Table 2). Under the

Table 2 Weight percentage composition of the two compared refractory bricks

\begin{tabular}{lll}
\hline Raw material * & \multicolumn{2}{l}{ Mass percentage } \\
\cline { 2 - 3 } & $\begin{array}{l}\text { MgO-C } \\
\text { reference } \\
\text { bricks }\end{array}$ & Carbonless bricks \\
\hline DBM97 & 21 & 79.88 \\
$\mathrm{MA} \mathrm{sintered} \mathrm{spinel} \mathrm{"MR66"} \mathrm{(67 \%}^{*}$ & $/$ & 10.98 \\
$\left.\mathrm{Al}_{2} \mathrm{O}_{3} / 32 \% \mathrm{MgO}\right)$ & & \\
$\mathrm{FM}^{2}$ & 60 & $/$ \\
Graphite & 12 & $/$ \\
Phenolic resin & 5 & $/$ \\
Antioxidants (silicon) & 2 & $/$ \\
Tabular alumina & $/$ & 4 \\
Reactive alumina & $/$ & 4 \\
Clay & $/$ & 1 \\
Carboxylic acid salt of Aluminum & $/$ & 0.15 \\
Total & 100 & 100 \\
\hline
\end{tabular}

* DBM: dead burnt magnesia; FM: fused magnesia; MA: magnesium-aluminate ; 97: attained purity grade of $97 \%$ of magnesia content; MR66: "magnesia-rich" MA sintered spinel 
cautionary pessimistic assumption of the absence of any flue gases confinement and pollutant abatement system, consequently, the LCI of the emitted substances, drawn from Irie and Rappolt (2010), has been updated accordingly, as reported in Table 1. These emissions are computed separately from those arising from the gas burning process for pre-heating purposes (as illustrated in "Additional impacts deriving from the operational procedures of the ladle Section") and, even though actually take place at the steel manufacturing plant, can be computed within the brick manufacturing process, because, in this way, can be easily attributed to this type of bricks lining. This simplification, without consequences on the analysis, is functional to the successive step of shifting the functional unit to the steel produced, whereas the computation of the emissions exactly at the place of origin can assume importance in the case of geographically differentiated impact assessments, which is not the case of the present paper.

It must be underlined that the previous assumption regarding the LCI of the emissions is pessimistic since it is well known that the pre-heating procedure of the refractory material in the presence of organic binders is characterized by a substantial emission of hydrocarbons, some of which carcinogenic, as PAHs (i.e., benzo[a]pyrene, classified in Group 1 according to the IARC classification, and many others classified in Groups 2A and 2B, as reported by Jameson 2019) and phenols (Moch et al. 2008). For this reason, ladles in pre-heating stations are conventionally equipped with expensive enclosures (Ebner et al. 2017; Moch et al. 2008), having the primary function of limiting heat losses by radiation and in some cases provided with heat recovery systems from the hot flue gas and post-combustion systems to limit the emission of the above-mentioned highly pollutant and hazardous substances. For example in Moch et al. (2008), specifically designed heat recovery systems and a suction hood design were investigated. Nevertheless, in current industrial practice, the presence of such refined systems is not a certainty at each site and uncontrolled leaks of the exhaust gas could affect the workplace and the environment, as also reported in Moch et al. (2008).

In the course of the research project, the results of the preliminary laboratory and industrial trials with the initial experimental recipes for carbonless bricks were unsatisfactory. A major flaw was represented by the unacceptable rate of degradation of the surface of the bricks, even in the upper part of a ladle put into operation, where some of these bricks were installed, quite far from the slag line (zone of the ladle subject to the most severe conditions, together with the bottom part). Therefore, from the initial recipes, an example of which is presented in Table 1 (p. 5) in Boenzi et al. (2019), a new formulation was developed, making use of magnesium-aluminate (MA) sintered spinel as novelty component. In Table 2, the recipes of the compared refractory bricks are reported (different particle size distributions are undisclosed for industrial privacy reasons).

As regards the LCIs of the production processes of the basic magnesia-based components, "DBM97," cannot be assimilated to ordinary dead burned magnesia (ODBM) as described for example in $\mathrm{Li}$ et al. (2016) because its $\mathrm{MgO}$ content is higher than $89-92 \%$. Instead, it has been considered equivalent to and substituted by high-purity magnesia (HPM) (96-97.7\% MgO) illustrated in the same paper, with the relative LCI of the production process. The LCI of the production process of "FM97" is considered equivalent to that of fused magnesia (FM), also illustrated in $\mathrm{Li}$ et al. (2016), since the purity grade of $96-97.8 \%$ of $\mathrm{MgO}$ is comparable. The LCIs of the magnesite mining process and of all the other ingredients appearing in Table 2 can be found in Boenzi et al. (2019), except for magnesium-aluminate sintered spinel, described in the next section.

\section{Magnesium-Aluminate (MA) sintered spinel production process}

The novelty component of the new carbonless recipe (with respect to previously defined and partially tested recipes) is the introduction of MA sintered spinel (specifically, magnesia-rich "MR66" type), accounting for around $11 \%$ in weight. Spinel $\left(\mathrm{MgAl}_{2} \mathrm{O}_{4}\right)$ is the only intermediate compound in the phase diagram of the system $\mathrm{MgO}-\mathrm{Al}_{2} \mathrm{O}_{3}$, with a congruent melting point at $2135{ }^{\circ} \mathrm{C}$ (Braulio et al. 2011; Schmidtmeier et al. 2009). At temperatures below $1300 \mathrm{~K}$, spinel is shown as a line compound, occurring at an exact equimolar fraction of $\mathrm{MgO}$ and $\mathrm{Al}_{2} \mathrm{O}_{3}$ (ratio $\mathrm{MgO} / \mathrm{Al}_{2} \mathrm{O}_{3}$ equal to $28.3 / 71.7$ by weight), while, above this temperature, the spinel phase can exhibit considerable non-stoichiometric behavior, deviating from that composition. In nature, as also in synthetic products, the ratio $\mathrm{MgO} / \mathrm{Al}_{2} \mathrm{O}_{3}$ can vary within wide limits. If the amount of magnesia is higher than that of pure spinel composition, it is known as "magnesia-rich" spinel (MR); vice-versa if the amount of alumina is higher than the alumina content of pure spinel, it is known as "alumina-rich" spinel (AR). Commercially, there are many grades of such spinels (known as "MR 66," "AR 78," "AR 90"), characterized by several compositions (Canikoğlu and Toplan 2016). According to Zhang and Lee (2004), the most ancient, easiest, but still extensively used method for the synthesis of MA spinel is the "Conventional Oxide Mixing" (CMO), or solid-solid reaction technique, in which powder $\mathrm{MgO}$ and $\mathrm{Al}_{2} \mathrm{O}_{3}$ bearing compounds (e.g., oxides, hydroxides, or carbonates) are mixed, shaped and sintered at high temperature for extended times. The resulting mass is then pounded to powders of the preferred size distribution. The mechanism of formation of spinel via CMO 
has been explored widely, involving a complex counter diffusion process, in which $\mathrm{Mg}^{+2}$ ions and $\mathrm{Al}^{+3}$ ions diffuse away from the $\mathrm{MgO}-\mathrm{MgAl}_{2} \mathrm{O}_{4}$ interface in opposite directions. For the industrial production of sintered MA spinel, different starting materials can be employed. For example, according to the industrial reference Erzkontor (2021), it can be produced from caustic magnesia (highly reactive magnesium oxide) and alumina or bauxite $\left(\mathrm{Al}(\mathrm{OH})_{3}\right)$ in briquetted form, mixed in the required ratio and fired, in a rotary kiln, at the temperature of approximately $1800{ }^{\circ} \mathrm{C}$ or, as in the case considered in Ozkan et al. (2016), starting from magnesite $\left(\mathrm{MgCO}_{3}\right)$ and alumina. In the same paper, it is reported that direct starting materials can be high-purity grade magnesia and alumina ("Most refractory grade sintered spinels are made from a combination of high-purity synthetic aluminum oxide $\left(\mathrm{Al}_{2} \mathrm{O}_{3}\right)$ and chemical-grade $\left.\mathrm{MgO}^{\prime \prime}\right)$, as also reported in Kriechbaum et al. (1992), from which the general process flow illustrated in Fig. 1 is drawn. Sample points are implemented at various stages of the process, starting from the check of the chemical purity of raw materials; these raw materials are co-milled and then granulated with water and dried. Sintering and firing at temperatures higher than $1850{ }^{\circ} \mathrm{C}$ is the key step of the process, obtaining the sintered ball-shaped granulate. Finally, the granulate is cooled and crushed/ground to the desired size.

\section{Calculations of the energy required for sintering MA spinel}

Because of the lack of specific industrial data regarding the energy requirements for this process, an extrapolation from the data found in Ozkan et al. (2016) has been carried out. The basic reference for the calculations is the Life Cycle Inventory reported in Table 3 (p. 5) of that paper, in which the considered starting materials for the formation of refractory grade sintered spinel are magnesite $\left(\mathrm{MgCO}_{3}\right)$ and alumina. In the current context, as also specified above, it is more logical to consider the production process starting directly from industrially produced magnesia and alumina. In order to utilize the data illustrated in Ozkan et al. (2016) (deriving from an industrial case) likewise, it is necessary to derive the thermal energy required for sintering MA spinel as the calculated difference between the datum referring to the total required thermal energy and the heat for the calcination (decarbonation) reaction only of $\mathrm{MgCO}_{3}$. The relevant data used, considering one metric tonne $(1000 \mathrm{~kg})$ as the functional unit, are summarized in Table 3, in which some corrections and adaptations, illustrated hereafter, have been employed. It is also assumed that the final conversion degree of the input materials into spinel $\mathrm{MgAl}_{2} \mathrm{O}_{4}$ is practically complete; also the possible use of mineralizers for increasing the spinel formation rate is neglected, being always implemented with very small amounts (Zhang and Lee 2004).

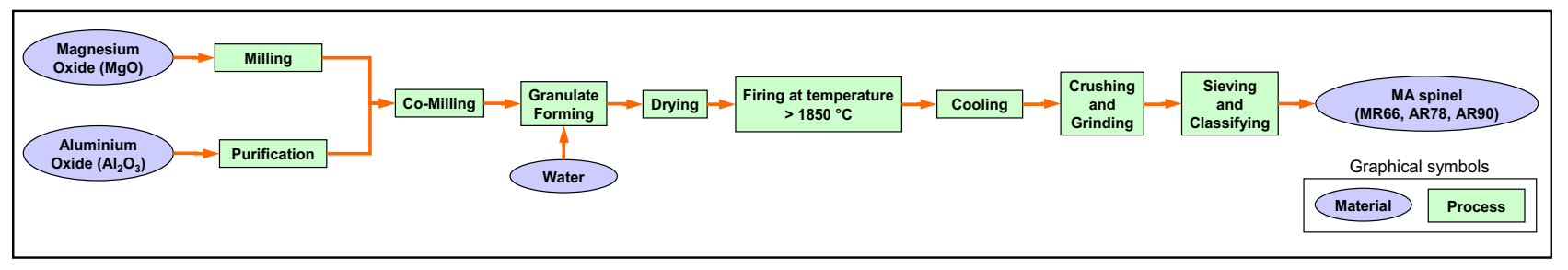

Fig. 1 MA sintered spinel general process flow drawn and adapted from Kriechbaum et al. 1992

Table 3 Relevant data and related assumptions for the sintering process of one tonne of MA spinel

Life cycle inventory input data for one tonne of sintered spinel: original data found in Ozkan et al. (2016) and corrected amounts

\begin{tabular}{|c|c|c|c|c|}
\hline Materials and Energy & Amount & Corrected amount & Materials and Energy & Amount \\
\hline $\mathrm{MgCO}_{3}$ (natural resource) & $688 \mathrm{~kg}$ & $700.71 \mathrm{~kg}$ & $\mathrm{MgO}$ & $323.23 \mathrm{~kg}$ \\
\hline $\mathrm{Al}_{2} \mathrm{O}_{3}$ & $653 \mathrm{~kg}$ & $665.06 \mathrm{~kg}$ & $\mathrm{Al}_{2} \mathrm{O}_{3}$ & $676.77 \mathrm{~kg}$ \\
\hline \multirow[t]{2}{*}{ Heavy fuel oil (thermal energy) } & $3.52 \mathrm{GJ}$ & 3.585 GJ & $\begin{array}{l}\text { Calculated thermal energy for calcination } \\
\text { only of the corrected mass of } \mathrm{MgCO}_{3}\end{array}$ & $0.8976 \div 0.981 \mathrm{GJ}$ \\
\hline & & & Calculated thermal energy for sintering & $2.604 \div 2.687 \mathrm{GJ}$ \\
\hline Electricity & $72.22 \mathrm{kWh}$ & $73.554 \mathrm{kWh}$ & Electricity & $73.554 \mathrm{kWh}$ \\
\hline $\begin{array}{l}\text { Output material (refractory grade } \\
\text { sintered spinel) }\end{array}$ & $981.864 \mathrm{~kg}$ & $1000 \mathrm{~kg}$ & Output material (MR66 sintered spinel) & $1000 \mathrm{~kg}$ \\
\hline
\end{tabular}

Corrected amounts, calculation data and assumptions for the sintering process of one tonne of MA spinel in this paper 
As above illustrated, the required firing temperature in order to obtain synthetically the solid-state reaction sintering of magnesia-alumina spinels is approximately $1800{ }^{\circ} \mathrm{C}$ or higher. Since, as illustrated in Sheila (1993), already at $1023 \mathrm{~K}$, the fraction of magnesite reacted is almost $100 \%$, at higher temperatures it is possible to assume the complete stoichiometric calcination process of magnesite into $\mathrm{MgO}$, according to the decarbonation reaction $\mathrm{MgCO}_{3}+\Delta \mathrm{H} \rightarrow \mathrm{MgO}+\mathrm{CO}_{2}$. The weight yield of $\mathrm{MgO}$ in the reaction is 0.478 per unit mass of magnesite and, with $688 \mathrm{~kg}$ of $\mathrm{MgCO}_{3}$, the yield of $\mathrm{MgO}$ would be $328.864 \mathrm{~kg}$, which, added to $653 \mathrm{~kg}$ of $\mathrm{Al}_{2} \mathrm{O}_{3}$, would result in $981.864 \mathrm{~kg}$. The percentage content of $\mathrm{Al}_{2} \mathrm{O}_{3}$ of the obtained product is $653 \mathrm{~kg} / 981.864 \mathrm{~kg}=66.5 \%$ which is coherent with the MA spinel composition indicated by the industrial partner in the recipe (MR 66 spinel in Table 2). However, since the reference quantity of MA sintered spinel should be $1000 \mathrm{~kg}$, the original data reported in the second column of Table 3 have to be corrected accordingly, multiplying all the input values by $1000 / 981.864=1.01847$ (the corrected amounts are reported in the third column of the same table). As regards the heat of reaction $\Delta \mathrm{H}$ required by the process, literature sources indicate a value in the range $108 \mathrm{~kJ} / \mathrm{mol} \div 118 \mathrm{~kJ} / \mathrm{mol}$, respectively, found in Sheila (1993) and in Seeger et al. (2011). Assuming the molar mass of $\mathrm{MgCO}_{3}$ equal to $84.314 \mathrm{~g} / \mathrm{mol}$, it is possible to calculate $\Delta \mathrm{H}$ in the range $1281 \mathrm{~kJ} \div 1400 \mathrm{~kJ}$ per $\mathrm{kg}$ of $\mathrm{MgCO}_{3}$. Finally, the thermal energy for magnesite decarbonation only is calculated as the product of those values by the required amount $(700.71 \mathrm{~kg})$ and the thermal energy for sintering is derived as the difference from the corrected datum of 3.585 GJ. With a cautious approach, the higher value of $2.687 \mathrm{GJ}$ per tonne of MA sintered spinel is assumed.

\section{Modeling of MA spinel production, providers' processes and product transport}

The MA spinel production process has been created on purpose within the software OpenLCA version 1.7.4 (openLCA 2021), assuming the production plant located in Germany. As mentioned above, the starting materials for the process are magnesia and alumina, industrially produced with highpurity grades, in the assumed proportion $67 \% \mathrm{Al}_{2} \mathrm{O}_{3} / 32 \%$ $\mathrm{MgO}$ (plus minor components and impurities), corresponding to the commercially designated MR 66 (magnesia-rich) spinel. In the Ecoinvent 3.4 database (The ecoinvent Database 2017) these flows are available as products on the global markets in the form of output from the Unit processes "market for aluminum oxide I Cutoff, U - GLO" and "market for magnesium oxide I Cutoff, U - GLO," respectively. Hypothesizing a purity grade of $99 \%$, an increment of $1000 / 990=1.01$ on both percentages is applied so that $676.77 \mathrm{~kg}$ of $\mathrm{Al}_{2} \mathrm{O}_{3}$ and $323.23 \mathrm{~kg}$ of $\mathrm{MgO}$ are utilized as input materials of the created process (fifth column in Table 3). The upstream processes for both market processes, with default values, comprise transports (a mix of freight train, freight lorry and ship transports) and production. In particular, in the first dataset, it is assumed that of all aluminum oxide present on the market $96.7 \%$ comes from "aluminum oxide production I Cutoff, U - GLO" (assumed average technology for the aluminum produced globally) and the remaining part from aluminum scrap recycling ("treatment of aluminum scrap, new, at refiner I Cutoff, U" and "treatment of aluminum scrap, post-consumer, prepared for recycling, at refiner I Cutoff, U," localized partly in Europe and partly outside Europe). In the second dataset, magnesium oxide on the market comes entirely from the production process "magnesium oxide production I Cutoff, U," assumed localized $82.6 \%$ outside Europe and $17.4 \%$ in Europe. As regards the energy inputs, the assumed amount of $2.687 \mathrm{GJ}$ of thermal energy, per tonne of MA produced, is considered supplied by the provider "heat production, natural gas, at industrial furnace $>100 \mathrm{~kW} \mathrm{I} \mathrm{heat,}$ district or industrial, natural gas I Cut-off, U -Europe without Switzerland," adopted also for other processes. The choice of this provider (heat from gas) derives from the consideration that the sintering process is performed in a rotary kiln (according to Erzkontor 2021) or in a shaft furnace (according to Keralit 2016), in any case adopting technological solutions very similar to those adopted for the production of tabular alumina (produced in a gas feeded shaft kiln). In addition, natural gas represents the cleaner form of fuel and would prevent the contamination of this high-tech product by flue gases and/or by the fuel itself.

The electrical energy consumption is assumed $73.55 \mathrm{kWh}$ / tonne (with a cautious approach since this datum, as above illustrated, comes from a plant in which $\mathrm{MgCO}_{3}$ is used, instead of $\mathrm{MgO}$ ), provided by the process "market for electricity, medium voltage I Cutoff, $\mathrm{U}-\mathrm{DE}$ " ( $\mathrm{DE}=$ Germany). Finally, transports are carried out by trucks covering a distance, from the German production site to the brick manufacturing plant in Spain, of around $1700 \mathrm{~km}$, with the provider "market for transport, freight, lorry, unspecified I Cut-off, U - GLO."

\section{Modeling of the carbonless bricks product system and brick manufacturing data}

The resulting product system for the production of the new carbonless magnesia and MA spinel-based bricks is summarized graphically in Fig. 2, reporting the involved production processes, along with material flows and logistic information about the distances from mine or production sites to the brick manufacturing plant. In particular, mining and production of "HPM" are assumed located in Turkey and the transports are performed by trucks and freight ship; MA sintered spinel is assumed produced and supplied by a manufacturer in Germany; the manufacturer and supplier of tabular and reactive aluminas is assumed located in France, as well as the clay 


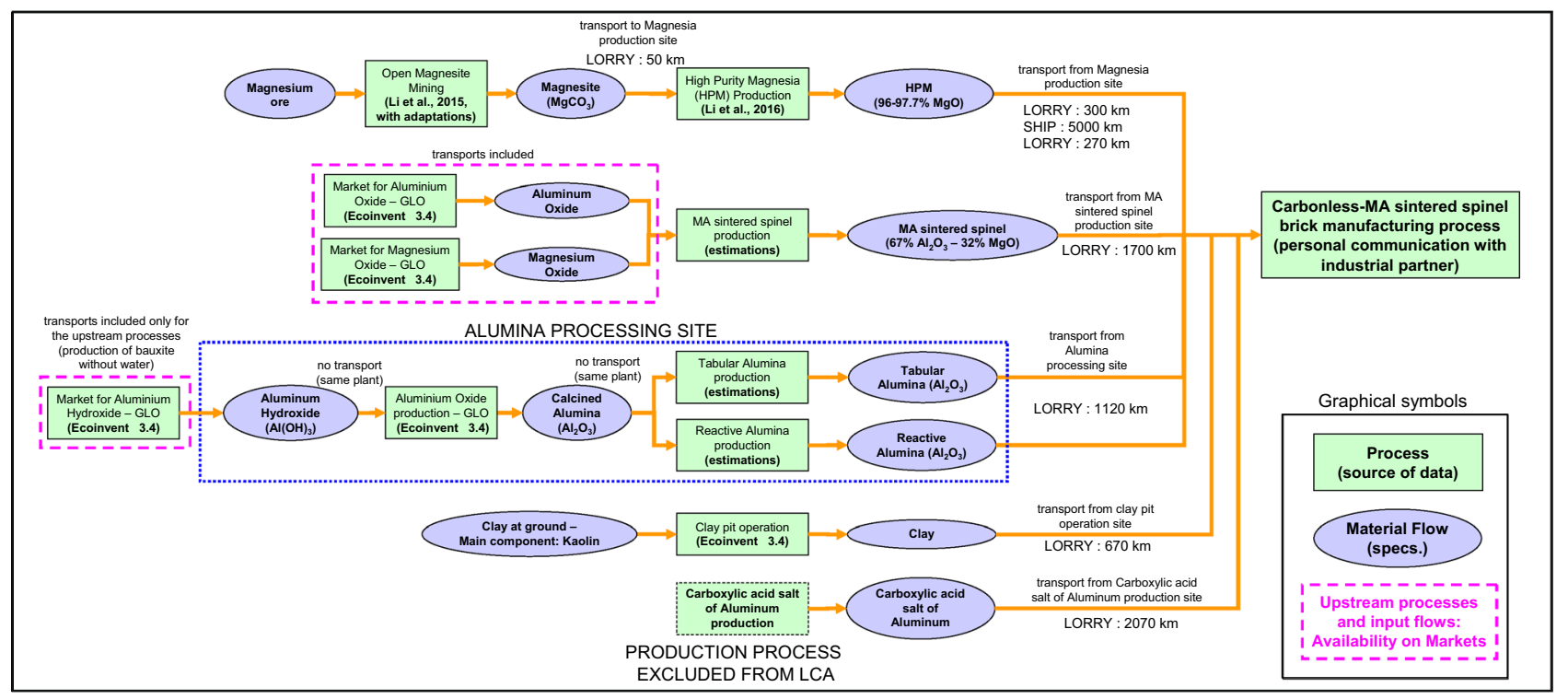

Fig. 2 Suppliers' chain for the production of the new "Carbonless" bricks (magnesia and MA sintered spinel as principal components)

mining and clay packaging site; finally, the component "Carboxylic acid salt of Aluminum" is excluded from the analysis, being present with a neglectable percentage. All the road transports, covering the distances specified in the figure, up to the brick manufacturing plant, are modeled with the provider "market for transport, freight, lorry, unspecifiedlcut-off, UGLO," while the sea transport is provided by the unit process "market for transport, freight, sea, transoceanic shiplcut-off, U-GLO."

As regards the carbonless brick manufacturing process, negligible weight losses during sintering are assumed; however, gaseous emissions of several substances can occur and should be taken into consideration. The industrial partners of the project have not characterized them, and also a survey on the available scientific literature has not provided information on the gaseous emissions during sintering with a similar chemical composition of the bricks. Anyway, in order to overcome this difficulty, at first approximation, the same gaseous emissions as those in Table 5 in Ozkan et al. (2016) have been assumed. In Table 4 the total percentage contents of $\mathrm{MgO}$ and $\mathrm{Al}_{2} \mathrm{O}_{3}$ are calculated, in order to compare quickly the gross compositions of the bricks. As observable, the chemical composition is slightly different, due to the higher content of alumina and the lower content of magnesia in the examined case.

Regarding the energy inputs of the brick manufacturing processes, the main differences between the two types of bricks are reported in Table 5. The optimum sintering temperature of the new carbonless bricks has been estimated by the industrial partners between 1725 and $1750^{\circ} \mathrm{C}$. Because of the lack of experimental data about the required thermal energy, the datum of the specific energy requirement for drying and firing (at $1760-1850^{\circ} \mathrm{C}$ ) magnesia bricks in tunnel kilns has
Table 4 Total content of $\mathrm{MgO}$ and $\mathrm{Al}_{2} \mathrm{O}_{3}$ for the considered carbonless refractory bricks

\begin{tabular}{|c|c|c|}
\hline \multirow{2}{*}{$\begin{array}{l}\text { Basic raw } \\
\text { material }\end{array}$} & \multicolumn{2}{|l|}{ Mass percentage } \\
\hline & $\begin{array}{l}\text { Magnesia spinel bricks (in } \\
\text { reference Ozkan et. 2016) }\end{array}$ & $\begin{array}{l}\text { Carbonless bricks } \\
\text { in this paper }\end{array}$ \\
\hline $\mathrm{MgO}$ & 89 & $83.395^{\mathrm{a}}$ \\
\hline $\mathrm{Al}_{2} \mathrm{O}_{3}$ & 9 & $15.347^{\mathrm{b}}$ \\
\hline Other & 2 & 1.258 \\
\hline Total & 100 & 100 \\
\hline
\end{tabular}

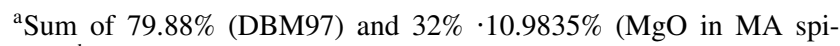

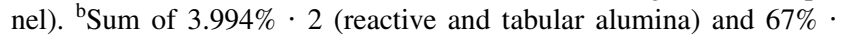
$10.9835 \%\left(\mathrm{Al}_{2} \mathrm{O}_{3}\right.$ in MA spinel)

been drawn from the reference document JRC (2007), assuming, from the reported range $6000-9700 \mathrm{~kJ} / \mathrm{kg}$, the lower value of $6000 \mathrm{~kJ} / \mathrm{kg}$ (or MJ/t), considering the asserted relatively low sintering temperature. The energy consumption for the $\mathrm{MgO}-\mathrm{C}$ reference bricks has been assumed around one-third of that figure, on the basis of information provided by the industrial partners. The heat provider in the LCI of both the brick manufacturing processes chosen in the Ecoinvent 3.4 database as the most fit is the Unit Process "heat production, natural gas, at industrial furnace $>100 \mathrm{~kW}$ I heat, district or industrial, natural gas I cut-off - Europe without Switzerland," since the tunnel kiln is fed by natural gas.

\section{Theoretical formulation for shifting the impacts of the Functional Unit from bricks to steel}

In order to extend the LCIA analysis to the real possible advantage that the new developed carbonless bricks could 
Table 5 Manufacturing process and main differences between the two types of bricks

Phase \& Equipment

Molding Phase in a Hydraulic Press ${ }^{1}$

Baking/Sintering Phase in a Gas Combustion Tunnel Kiln

Type of pressing

Temperature and duration

Energy Consump-

tion (thermal

energy)

$\mathrm{MgO}-\mathrm{C}$ Reference Bricks

Carbonless Bricks
Single press cycle at $2000 \mathrm{t}$

Single press cycle at $1600 \mathrm{t}$
$200{ }^{\circ} \mathrm{C}$ for $24 \mathrm{~h}$

Drying and sintering at around $1750{ }^{\circ} \mathrm{C}$ for several hours
$1800 \mathrm{MJ} / \mathrm{t}$

$6000 \mathrm{MJ} / \mathrm{t}$

${ }^{1}$ Electrical energy consumption assumed negligible with respect to the thermal energy

offer in the production of steel, it is necessary to calculate the consumption of bricks in the entire ladle life, before complete re-lining, in both cases, i.e., in the reference case and adopting the carbonless bricks.

The following notation is introduced, in which [t] represents one metric tonne $(1000 \mathrm{~kg})$, with specified subscripts:

- RLC: Reference Ladle Capacity in terms of mass of liquid steel $\left[t_{\mathrm{LS}}\right]$

- NNH: Nominal Number of Heats (average value) before complete re-lining of the reference ladle;

- $\mathrm{cp}_{\mathrm{s}}$ : compliant percentage of steel (high-quality steel grade) obtained at each heat, assumed as a constant value and independently from the type of refractory brick lining $\left[t_{\text {Steel }} / t_{\mathrm{LS}}\right]$;

- $\mathrm{LM}_{B}$ : Lining Mass of refractory bricks required by the reference ladle $\left[t_{\text {Bricks }}\right]$;

- mc: maintenance coefficient, defined as the ratio of the total mass of bricks required during intermediate partial re-lining interventions over $\mathrm{LM}_{B}$;

- $\mathrm{TM}_{B}$ : Total Mass of Bricks used in the entire ladle life $\left[t_{\text {Bricks }}\right]$;

- $\mathrm{TM}_{S}$ : Total Mass of Steel, compliant with high-quality grade, produced in the entire ladle life before re-lining $\left[t_{\text {Steel }}\right]$

- SC: Specific Consumption of the refractory material, defined as the ratio of $\mathrm{TM}_{B}$ over $\mathrm{TM}_{S}\left[t_{\text {Bricks }} / t_{\text {Steel }}\right]$;

- $i$ : impact category $i$-th of the adopted impact assessment methodology; specifically, with ReCiPe 2016, $i \in\{1,2, \ldots, 18\}$;

- Impact* $*_{i}$ : value of the $i$-th impact category referred to one tonne of bricks [specific unit / $t_{\text {Bricks }}$;
- Impact $_{i}$ : value of the $i$-th impact category referred to one tonne of steel produced [specific unit $/ t_{\text {Steel }}$; (to all the above terms, except for the first one, the subscripts "MgO-C" or "Carbonless" can be added in order to identify the case of the use of the reference bricks or of the carbonless ones for the ladle lining, respectively). The following equations can be derived:

$\mathrm{TM}_{S}=\mathrm{RLC} \times \mathrm{cp}_{S} \times \mathrm{NNH}$,

$\mathrm{TM}_{B}=\mathrm{LM}_{B} \times(1+\mathrm{mc})$,

$\mathrm{SC}=\frac{\mathrm{TM}_{B}}{\mathrm{TM}_{S}}$

Therefore, in order to shift the calculated values of the impacts from one tonne of bricks to one tonne of produced steel, the following relation is employed:

$\operatorname{Impact}_{i}\left[\right.$ specific unit $\left./ t_{\text {Steel }}\right]=\operatorname{Impact}_{i}^{*}\left[\right.$ specific unit $\left./ t_{\text {Bricks }}\right] \times \mathrm{SC}$.

This calculation takes into account only the ecological impacts due to the diversities between the two brick product systems and does not include the impacts arising from differences in the ladle operation modality in its entire life (before brick lining demolition and complete rebuilding), which are illustrated in the following. Introduced the factors $r f_{i}$ for each $i$-th impact category (reduction or increment factor), defined as the following ratios (values reported in the 4th column of Table S1 in "Supplementary Appendix"):

$r f_{i}=\frac{\text { Impact }_{i \text {-Carbonless }}^{*}}{\text { Impact }_{i-\mathrm{MgO}-\mathrm{C}}^{*}}, \forall i \in\{1,2, \ldots, 18\}$

from Eq. (4) it is possible to derive the ratios:

$\frac{\text { Impact }_{i-\text { Carbonless }}}{\text { Impact }_{i-\text { MgO-C }}}=\frac{\text { Impact }_{i-\text { Carbonless }}^{*} \cdot \mathrm{SC}_{\text {Carbonless }}}{\text { Impact }_{i-\text { MgO-C }}^{*} \cdot \mathrm{SC}_{\text {MgO-C }}}=r f_{i} \cdot \frac{\mathrm{SC}_{\text {Carbonless }}}{\mathrm{SC}_{\text {MgO-C }}}, \forall i \in\{1,2, \ldots, 18\}$ 
Therefore, for the $i$-th impact category, it is advantageous to utilize the carbonless bricks only if the above ratio remains lower than 1 :

$r f_{i} \cdot \frac{\mathrm{SC}_{\text {Carbonless }}}{\mathrm{SC}_{\mathrm{MgO}-\mathrm{C}}}<1$,

$r f_{i}<\frac{\mathrm{SC}_{\mathrm{MgO}-\mathrm{C}}}{\mathrm{SC}_{\text {Carbonless }}}$

\section{Additional impacts deriving from the operational procedures of the ladle}

On the basis of information provided by the project partners, further ecological impacts associated with the production of steel must be taken into account when comparing the current situation (employing the traditional $\mathrm{MgO}-\mathrm{C}$ bricks ladle lining) to the forecast ones, adopting the carbonless bricks lining. The differences of these impacts arise from the ladle operational diversities with the two ladle linings and are due, on the one hand, to the consumption of natural gas and, on the other hand, to the consumption of electrical energy, both for heating purposes. back into operation has been quantified as around half the quantity used for the pre-heating phase.

Introduced the following general notation:

- Heat ${ }_{\text {gas }}$ : heating energy from gas for the pre-heating of the ladle before the start of its operation and after the partial re-lining intervention [GJ];

- $N_{\text {pre-heating: }}$ number of pre-heating operations (equal to the number of re-lining interventions plus one);

- Heat ${ }_{\text {gas-m.stop }}$ : heating energy from gas required to put the ladle back into operation after each weekly maintenance stop [GJ];

- $N_{\text {Stop }}:$ number of weekly maintenance stops in the entire ladle life;

- Impact $_{i \text {-Heatgas: }}$ calculated figure of the $i$-th impact category due to the consumption of the amount Heat ${ }_{\text {gas }}$ of energy from gas [specific unit];

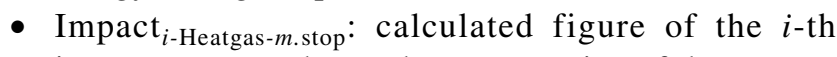
impact category due to the consumption of the amount Heat $_{\text {gas- } m \text {.stop }}$ of energy from gas [specific unit];

it is possible to calculate the specific impacts (per unit of steel produced, considering the entire ladle life) stemming from the gas consumption, for each category, as:

$$
\begin{aligned}
& \text { Impact }_{i-\text { Gas Consumption }}\left[\frac{\text { specific unit }}{t_{\text {steel }}}\right] \\
& =\frac{\text { Impact }_{i-\text { Heatgas }}[\text { specific unit }] \cdot N_{\text {pre }- \text { heating }}+\text { Impact }_{i-\text { Heatgas }- \text { m.stop }}[\text { specific unit }] \cdot N_{\text {stop }}}{\operatorname{TM}_{S}\left[t_{\text {steel }}\right]} .
\end{aligned}
$$

Regarding the gas consumption, the putting into operation of the ladle requires a pre-heating period, lasting several hours, for complete drying and pre-heating purposes of the lining refractory material, carried out by means of specifically designed gas burners; the same amount of gas is required after the intervention for partial re-lining (at around half the expected ladle life). The fundamental importance of the pre-heating procedure resides both in safety reasons, since moisture, entrapped in the refractory, at the contact with the molten steel would suddenly become steam, with the consequent risk of an explosion and in operational needs. They prescribe limiting the thermal shock of the refractory material (strongly influencing the ladle life) (Glaser et al. 2011; Ioana et al. 2017; Moch et al. 2008) and avoiding the skull formation (metal solidification in the ladle), which requires maintenance time and labor for its removal, because potentially affecting the steel quality and the pouring process. Furthermore, on the basis of information provided by the industrial partner, the ladle undergoes weekly maintenance stops (in terms of heats, at around each 20 heats) and the consumption of natural gas for the heating and putting
On the basis of the information provided regarding the required energy from gas after each maintenance stop with the currently employed lining (around half the quantity used for the pre-heating phase), reflected by the associated impacts, it is possible to write:

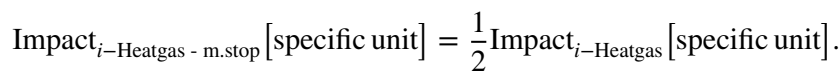

The above relation can be reasonably assumed maintained in analogy for different types of refractory lining and for the carbonless lining too. Therefore, Eq. (8a) can be re-written as:

$$
\begin{aligned}
& \text { Impact }_{i-\text { Gas Consumption }_{\text {spe }}\left[\frac{\text { specific unit }}{t_{\text {steel }}}\right]} \\
& =\frac{\text { Impact }_{i-\text { Heatgas }}[\text { specific unit }] \cdot\left(N_{\text {pre - heating }}+\frac{1}{2} N_{\text {stop }} \cdot\right)}{\mathrm{TM}_{S}\left[t_{\text {steel }}\right]} \\
& =\text { Impact }_{i-\text { Heatgas }}[\text { specific unit }] \cdot \text { Mlp.F. }\left[\frac{1}{t_{\text {steel }}}\right],
\end{aligned}
$$

in which the multiplicative factor Mlp.F. is introduced, with the function of comprising the shift of the impacts arising from gas burning to the quantity of steel produced. 
As regards the second additional contribution coming from the electrical energy consumption for heating the molten steel during the ladle operations (per single heat), it is characterized by the specific consumption parameter $E n_{\text {.electric }}\left[\mathrm{kWh}_{\mathrm{el}} / t_{\text {Steel }}\right]$ and by the associated impacts Impact $_{i-E n \text {.electric }}$.

Finally, adding up the contributions deriving from the three terms (brick product system, gas consumption and electrical energy consumption), it is possible to derive the overall resulting impact for each category as: information provided by the industrial partners of the project, the average number of heats before re-lining $(N N H)$ can be reasonably assumed as 80 heats, with a reference ladle capacity $(R L C)$ of $135 \mathrm{t}$, as really employed in the industrial site. Moreover, at a moment in time around half the expected ladle life, that is to say at 40 heats, a partial re-lining is carried out. In particular, it consists of the substitution of the slag line part of the lining, as also reported in Arteaga et al. (2014), using a total mass of bricks equal to around one half the value of $L M_{B}$, so that $m c$ in Eq. (2) equals 0.5 .

Impact $_{i-\text { overall }}\left[\frac{\text { specific unit }}{t_{\text {steel }}}\right]=$

$=\operatorname{Impact}_{i}^{*}\left[\frac{\text { specific unit }}{t_{\text {bricks }}}\right] \cdot \mathrm{SC}\left[\frac{t_{\text {bricks }}}{t_{\text {steel }}}\right]+$ Impact $_{i-\text { Heatgas }}[$ specific unit $] \times M l p . F .\left[\frac{1}{t_{\text {steel }}}\right]+\operatorname{Impact}_{i-E n \text {.electric }}\left[\frac{\text { specific unit }^{(10)}}{t_{\text {steel }}}\right]$,

with the proper subscript for each term.

\section{Results and discussion}

The chosen LCIA (Life Cycle Impact Assessment) methodology is the most recent version of the methodology "ReCiPe" (year 2016 - version 1.1) (Huijbregts et al. 2017a and 2017b), in its midpoint impact characterization model, in direct relation with the environmental flows (emissions or resource extractions), determining the impact pathway. This choice implies lowest uncertainty regarding the calculation of the impact indicators and less debatable controversies regarding the cause-effect chain; furthermore, it permits easier interpretations of the results in identifying the immediate causes of major impacts. The chosen time-horizon perspective (among the three available "Egalitarian," "Individualist" and "Hierarchist") is the "Hierarchist" one, being driven by scientific consensus and often considered the default model. Within the utilized software openLCA version 1.7.4 (openLCA 2021), the implementation of the updated methodology is performed by means of the package "openLCA LCIA methods" version 2.0.3, developed by the same software firm.

\section{Results of shifting the impacts of the Functional Unit from bricks to steel considering the refractory consumption only}

From inequality (7b), it is evident how the knowledge of the consumption of refractory bricks in ladle steel production assumes a fundamental importance for assessing the existence of a real advantage. At this regard, in the case of lining with the traditional reference $\mathrm{MgO}-\mathrm{C}$ bricks, on the basis of
Assuming around $30 \mathrm{t}$ as the total mass of $\mathrm{MgO}-\mathrm{C}$ lining bricks, as reported by the industrial partners, the refractory specific consumption $(S C)$ would result $4.6 \mathrm{~kg}$ per tonne of steel produced or $4.17 \mathrm{~kg} / \mathrm{t}$ considering liquid steel (without the $c p_{S}$ factor). It is important to underline that this consumption calculation refers to the input refractory material totally employed in the ladle lifetime and does not refer to the refractory wearing nor to the spent refractory material (the material resulting as output from the demolition of the lining).

Keeping in mind this point, the previous calculated values are coherent with those reported in the literature, as for example in JRC (2013), with the consumption of refractory lining in EAFs being in the extremely wide range $4-60 \mathrm{~kg} /$ $\mathrm{t}_{\mathrm{LS}}$, or by Hubble (1998), reporting the two values $3.6 \mathrm{~kg} /$ ton $(3.97 \mathrm{~kg} /$ tonne $)$ and $4.05 \mathrm{~kg} / \mathrm{ton}(4.64 \mathrm{~kg} /$ tonne $)$ for steel ladles and ladle metallurgy operations in two plants in USA (integrated and non-integrated, respectively). Further general data (not specifically referred to ladle furnaces) can be found in Domínguez et al. (2010), reporting a consumption of refractory bricks in the range $2-8 \mathrm{~kg} / \mathrm{T}_{\mathrm{m}}$ (probably, per metric ton), in Cappel (2007) and in Koros (2003), highlighting the time-decreasing consumption trend in the steel industry in general, as low as $14 \mathrm{lb} / \mathrm{NT}$ in $1998(6.35 \mathrm{~kg} /$ tonne if NT stands for metric tonne). As regards the ladle lifetime in terms of number of heats, besides the data provided by the industrial partners, in Arteaga et al. (2014) a general time increasing average number around 70 is reported in 2012 for $135 \mathrm{t}$ ladles, and in Ewais (2004) the datum of 95 heats is reported for a $95 \mathrm{t}$ ladle furnace lined with resin-bonded alumina/magnesia/ graphite bricks at the barrel and bottom and MgO-C at the slag area. In Kuznetsov et al. (2003), optimally tuned operating conditions of steel-teeming ladles permitted to reach, in the course of the years, till year 2000, the number of 75-90 heats (without mid-life repair) and the refractory consumption in the range $2.7-2.9 \mathrm{~kg} / \mathrm{t}$. In 
Kirschen et al. (2012), the ladle lifetime of magnesia linings is reported in the wide range $50-150$ heats, since the dissolution in the slag is strongly dependent on the $\mathrm{MgO}$ saturation level. In any case, as observed in the literature, the above data are very variable and can even change from plant to plant of the same steel producing company, depending from several factors: the nature of the used refractory, which can be affected and worn in diverse manners by the formed slag (slag attack), the type of steel produced (because of the production of different steel grades), the nature of slag formers, the operational and process conditions of the ladles, involving in particular the adopted methods for temperature control (in order to keep it high in the ladle cycle), aimed at limiting thermal and thermo-mechanical stresses on the refractory lining (Arteaga et al. 2014; Ewais 2004).

Concerning the lining with the new carbonless bricks, data from the project partners regarding the average ladle life are not available, since experimentation is still in progress, proceeding with the partial substitution of the traditional $\mathrm{MgO}-\mathrm{C}$ bricks in different parts of the steel ladle. According to Ewais (2004), in a ladle with the capacity of $90 \mathrm{t}$ of molten steel, the replacement of fireclay bricks (33\% of $\mathrm{Al}_{2} \mathrm{O}_{3}$ ) with high-quality $65 \% \mathrm{Al}_{2} \mathrm{O}_{3}$ bricks enhanced the ladle life to 45 heats, whereas $\mathrm{MgO}-\mathrm{C}$ bricks are characterized by better performances. The thermo-mechanical properties of several carbonless refractory recipes developed in the course of the project, till the latest presented in this paper, have been studied extensively in controlled laboratory tests conditions (Wang et al. 2015; Wang and Sichen 2016; Wang et al. 2017; Svantesson et al. 2020). In particular, in the latter reference, $\mathrm{MgO}$-spinel-type refractories ( $87 \mathrm{wt} \% \mathrm{MgO}-9$ wt $\% \mathrm{Al}_{2} \mathrm{O}_{3}$ and $81 \mathrm{wt} \% \mathrm{MgO}-16 \mathrm{wt} \% \mathrm{Al}_{2} \mathrm{O}_{3}$ ) showed the most resistance toward the studied type of slag and deserve further research. The results of laboratory tests can disclose promising aspects but, as in the case of more traditional refractory linings, the ladle lifetime is very difficult to predict in the absence of on-site data at industrial scale, because of the variability of the operating conditions. On the basis of the above considerations, in order to carry out a reasonable comparison, in the present paper it has been assumed that the expected average number of heats with the new refractory lining could vary in the range 40-60 heats, but anyway remaining lower than 80 heats. More specifically, two hypothetical scenarios are formulated:

- a pessimistic scenario (a), characterized by an average value of 40 heats till ladle re-lining;

- an optimistic scenario (b), with 60 heats as average till ladle re-lining.

In both scenarios, also the ladle operational features are taken into account and forecast, on the basis of an analogy with the current case of $\mathrm{MgO}-\mathrm{C}$ refractory bricks lining. More in detail, also adopting the new carbonless bricks, the partial re-lining is foreseen occurring at half ladle life (20 heats in scenario (a) and 30 heats in scenario (b)) and requiring the same value 0.5 of $m c$ in Eq. (2). All the adopted data, both provided by the industrial partners and assumed, are summarized in Table 6.

Table 6 Essential data and assumptions for the transposition of the LCA from 1 tonne of bricks to 1 tonne of steel produced—analysis limited to the provision of lining refractory bricks

Common parameters

Data for the $\mathrm{MgO}-\mathrm{C}$ bricks lining

Data for the Carbonless bricks lining

$$
\begin{aligned}
& \mathrm{RLC}=135\left[t_{\mathrm{LS}}\right] \text { (Liquid Steel) } \\
& \mathrm{cp}_{\mathrm{S}}=0.9\left[t_{\text {Steel }} / \mathrm{t}_{\mathrm{LS}}\right] \\
& \mathrm{mc}=0.5 \\
& \rho_{\mathrm{MgO}-\mathrm{C}}=3.08\left[\mathrm{~g} / \mathrm{cm}^{3}\right] \text { or }\left[\mathrm{t} / \mathrm{m}^{3}\right] \\
& \mathrm{LM}_{B \mathrm{MgO}-\mathrm{C}}=30\left[t_{\text {Bricks MgO-C }}\right] \\
& \mathrm{TM}_{B \mathrm{MgO}-\mathrm{C}}=\mathrm{LM}_{B \mathrm{MgO}-\mathrm{C}} \cdot(1+\mathrm{mc})=45\left[t_{\text {Bricks MgO-C }}\right] \\
& \mathrm{NNH}_{\mathrm{MgO}-\mathrm{C}}=80 \text { (Reference value) } \\
& \mathrm{TM}_{S \mathrm{MgO}-\mathrm{C}}=R L C \cdot c p_{S} \cdot \mathrm{NNH}_{\mathrm{MgO}-\mathrm{C}}=9720\left[t_{\text {Steel }}\right] \\
& \mathrm{SC}_{\mathrm{MgO}-\mathrm{C}}=\mathrm{TM}_{B \text { MgO-C }} / \mathrm{TM}_{S \mathrm{MgO}-\mathrm{C}}=4.63 \cdot 10^{-3}\left[t_{\text {Bricks MgO-C }} / t_{\text {Steel }}\right] \\
& \rho_{\text {Carbonless }}=3.03\left[\mathrm{~g} / \mathrm{cm}^{3}\right] \text { or }\left[\mathrm{t} / \mathrm{m}^{3}\right] \\
& \mathrm{LM}_{B \text { Carbonless }}=\rho_{\text {Carbonless }} / \rho_{\mathrm{MgO}-\mathrm{C}} \cdot \mathrm{LM}_{B \text { MgO-C }}=29.51 \\
& \text { [ } \left.t_{\text {Bricks Carbonless }}\right] \\
& \mathrm{TM}_{B \text { Carbonless }}=\mathrm{LM}_{B \text { Carbonless }} \cdot(1+m c)=44.27\left[t_{\text {Bricks Carbonless }}\right]
\end{aligned}
$$

Assumed data for the Carbonless bricks lining Scenario (a)

$$
\begin{aligned}
& \mathrm{NNH}_{\text {Carbonless }}=40 \\
& \mathrm{TM}_{S \text { Carbonless }}=4860\left[\mathrm{t}_{\text {Steel }}\right] \\
& \mathrm{SC}_{\text {Carbonless }}=9.11 \cdot 10^{-3}\left[\mathrm{t}_{\text {Bricks Carbonless }} / \mathrm{t}_{\text {Steel }}\right]
\end{aligned}
$$

$S C_{\text {MgO-C }} / S C_{\text {Carbonless }}$

$1 / 1.97$

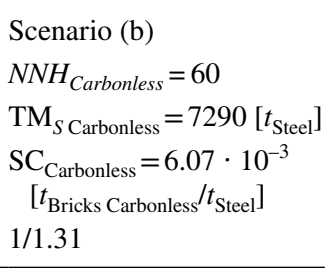




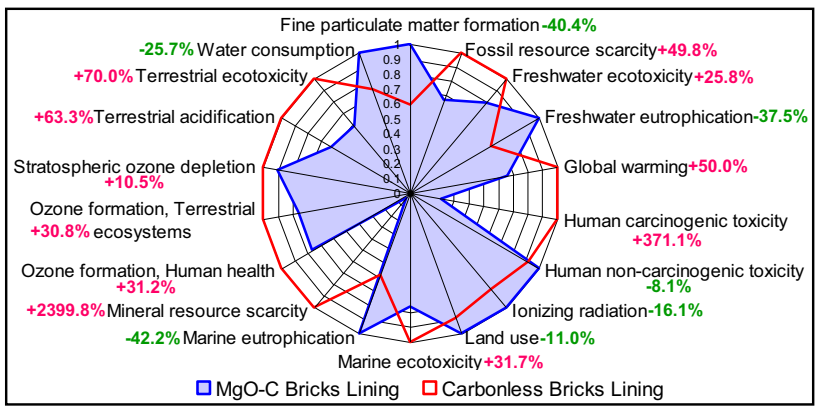

(a)

Fig. 3 Radar charts of the impact categories (ReCiPe 2016-version 1.1 , midpoint $\mathrm{H}$ ) as relative values of the reference $\mathrm{MgO}-\mathrm{C}$ bricks lining and of the carbonless bricks lining (F.U. $=1$ tonne of steel -

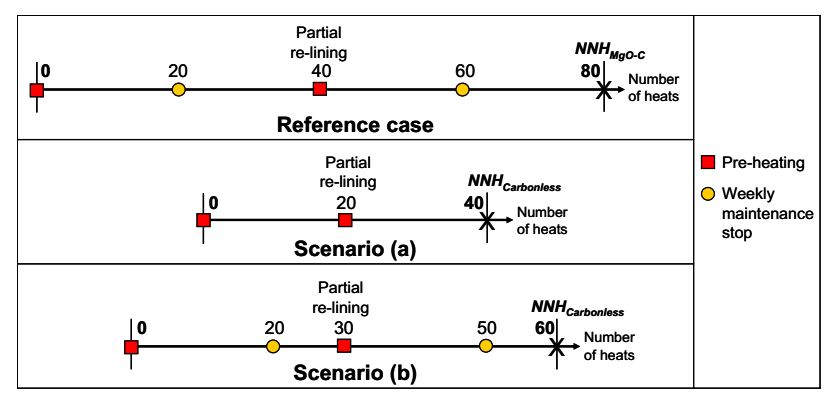

Fig. 4 Operational schemes of the ladle with the MgO-C lining (reference case) and with the carbonless lining in scenarios (a) and (b), according to the hypotheses

The above data allow to calculate, as reported in the last row of the table, the ratios of the values of SCs in inequality (7b), in the two hypotheses of forecast average number of heats with the carbonless bricks lining (affecting the

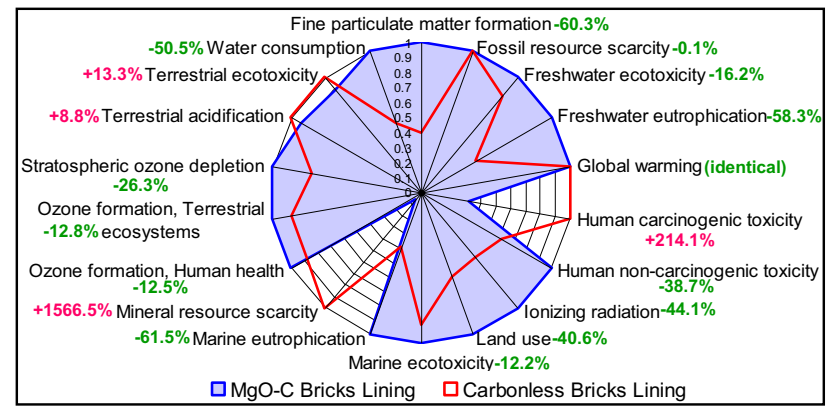

(b)

partial results: impacts of bricks lining only): $\mathbf{a}$ in scenario (a) with $N N H=40$ heats; $\mathbf{b}$ in scenario (b) with $N N H=60$ heats

parameter $N N H$ ), so that a comparison with the value of $r f_{i}$ to verify the inequality is possible.

In brief, considering the results in Table S1 in "Supplementary Appendix," in scenario (a) $r f_{i}$ remains lower than $1 / 1.97$ for the first seven impact categories only, while in scenario (b) it remains lower than $1 / 1.31$ for the first thirteen impact categories. This conclusion is confirmed and reported more in detail analyzing the results of the transposition of the impacts (F.U. $=1$ tonne of steel) calculated from Eq. (4), reported in the last two columns of Table S1 in the form of percentage differences w.r.t. the $\mathrm{MgO}-\mathrm{C}$ lining. Graphically, these results are depicted in the radar diagrams in Fig. 3 for the two scenarios (a) and (b); however, they must be intended as partial results (impacts in steel production from the provision of lining refractory bricks only), because also the additional impacts from gas burning and electricity consumption must be taken into consideration, as illustrated in the following section.

Table 7 Ladle operational data with the two different linings and in the two scenarios

Common data

Data for the MgO-C bricks lining

Assumed data for the Carbonless bricks lining

$$
\begin{aligned}
& \mathrm{TM}_{S \text { Carbonless }}=4860\left[t_{\text {Steel }}\right] \\
& N_{\text {pre-heating }}=2 \\
& N_{\text {Stop }}=0 \\
& M l p . F \cdot \text { Carbonless } \\
& \text { M. }
\end{aligned}
$$

Heat $_{\text {gas }}=194$ [GJ] (calculation based on the gas consump-

tion in one year and on the Lower Heating Value of

Heas $-m$. stop $_{\text {. }}=$ Heat $_{\text {gas }} / 2=97[\mathrm{GJ}]$

$N_{\text {pre-heating }}=2$

$N_{\text {Stop }}=2$

Mlp.F. $\cdot_{\mathrm{MgO}-\mathrm{C}}=3.08642 \cdot 10^{-4}\left[1 / t_{\text {Steel }}\right]$

Scenario (a)

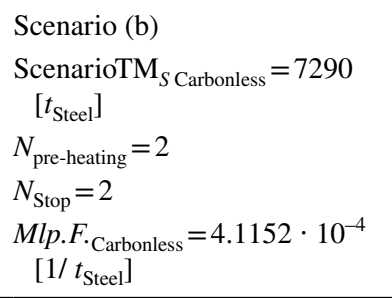




\section{Data for the additional impacts deriving from the operational procedures of the ladle}

Schematically, the operational features of the ladle in the three examined cases are reported in Fig. 4 and, on its basis, the calculation data used in Eqs. (8a) and (9) are summarized in Table 7.

In particular, it is possible to observe that in scenario (a), being the forecast average ladle life equal to 40 heats, the half-life partial re-lining would coincide with the weekly maintenance stop that in this case would not exist (zero for the parameter $N_{\text {stop }}$ ); in scenario (b), instead, the situation is analogous to that of the reference case. Consequently, the multiplicative factor Mlp.F. is the same for both scenarios and the impact contributions in Eq. (9) alike; this means that no differences exist, in terms of impact contributions from gas burning, between the two scenarios.

In order to calculate the values of the impact categories due to the quantity of energy Heat ${ }_{\text {gas }}$, missing more appropriate record data in the ecoinvent database, a specific process has been created within the software, considering for it just one heat provider, that is the unit process "heat production, natural gas, at industrial furnace $>100 \mathrm{~kW}$ I heat, district or industrial, natural gas I Cutoff, U-Europe without Switzerland," with its default providers. In this record dataset, the functional unit is the heat produced and the main aerial emission is represented by carbon dioxide. More in detail, for $1[\mathrm{MJ}]$ of output heat, 0.02699 [standard $\mathrm{m}^{3}$ ] of gas is required, with $0.0589[\mathrm{~kg}]$ of $\mathrm{CO}_{2}$ as output (from personal calculations the above data are coherent with the Norway composition of natural gas on the basis of data in Dones et al. (2007)). In the impact calculations, with the aim of avoiding the introduction of arbitrary efficiency factors, a slight over-estimation approach has been adopted and the parameter Heat ${ }_{\text {gas }}$ is used directly as the output of the process, while it should be reduced, being derived from the gas consumption data. The calculated impacts for this amount are then multiplied by the respective multiplicative factors in Table 7.

As regards the second additional contribution represented by the electrical energy consumption (per single heat), the relevant used data are reported in Table 8. The specific consumption parameter $E n_{\text {.electric }}\left[\mathrm{kWh}_{\mathrm{el}} / t_{\mathrm{Steel}}\right]$ has been calculated on the basis of information provided by the industrial partners, derived from measures for the reference $\mathrm{MgO}-\mathrm{C}$ lining. The resulting value of $65\left[\mathrm{kWh} \mathrm{el}_{\mathrm{el}} / t_{\text {Steel }}\right]$ is slightly greater than $50\left[\mathrm{kWh}_{\mathrm{el}} / t_{\text {Steel }}\right]$ reported by Dutta and Chokshi (2020). Instead, for the carbonless bricks lining, this parameter is a forecast value, foreseeing a reduction of the current figure to $90 \%$ thanks to the lower thermal conductivity of the refractory material, as for example the results illustrated by Santos et al. (2020) would suggest, referring to a potential reduction of $20 \%$ for "C-free" lining. No differences exist between scenarios (a) and (b) since the above data refer to single heats, not related to the different forecast lining life.

For impact modeling, a specific process has been created in the software, considering as provider of the amount $E n$.electric the market unit process "market for electricity, medium voltage I electricity, medium voltage I Cutoff, UES," located in Spain, with its default providers. The supply in medium voltage (between 1 and $24 \mathrm{kV}$ ) has been chosen since the consumption is probably detected at the electrical cabinet at this tension level, even if the electric arc heating is realized sourcing the electrodes at low voltage levels (hundreds of Volts). The associated impact categories Impact $_{i-E n \text {.electric }}$ are calculated for the $\mathrm{MgO}-\mathrm{C}$ lining and reduced to $90 \%$ for the carbonless lining.

The results of adding up the three impacts contributions deriving from the three terms (brick product system, gas consumption and electrical energy consumption), on the basis of Eq. (10), are reported in the following section.

\section{Comparison of the overall impact contributions}

Graphically, the comparison radar diagrams of the overall impact categories between the "baseline" case and each of the two scenarios are reported in Fig. 5. These diagrams highlight that the worsening of many impact categories found in the partial results in Fig. 3 is largely smoothed by the presence of the two additional contributions. In particular, the first two worsened impacts "Human carcinogenic toxicity" and "Mineral resource scarcity" are greatly reduced: in scenario (a) the first decreases from $+2400 \%$ to $+373 \%$ and the second from $+371 \%$ to $+117 \%$; in scenario (b), from $+1567 \%$ to $+241 \%$ and from $+214 \%$

Table 8 Electrical energy consumption with the current lining and foreseen data

Data for the $\mathrm{MgO}-\mathrm{C}$ bricks lining

Assumed data for the Carbonless bricks lining

\author{
Average Electrical Energy Consumption per Heat $=7900\left[\mathrm{kWh}_{\mathrm{el}}\right]$ \\ Mass of Steel produced per single Heat $=R L C \cdot c p_{S}=121.5\left[t_{\text {Steel }}\right]$ \\ En. electric-MgO-C $=7900\left[\mathrm{kWh}_{\mathrm{el}}\right] / 121.5\left[t_{\text {Steel }}\right]=65\left[\mathrm{kWh}_{\mathrm{el}} / t_{\text {Steel }}\right]$ \\ Forecast Average Electrical Energy Consumption per Heat $=7110\left[\mathrm{kWh}_{\mathrm{el}}\right]$ \\ Mass of Steel produced per single Heat $=R L C \cdot c p_{S}=121.5\left[t_{\text {Steel }}\right]$ \\ En. electric-Carbonless $=7110\left[\mathrm{kWh}_{\mathrm{el}}\right] / 121.5\left[t_{\text {Steel }}\right]=58.5\left[\mathrm{kWh}_{\mathrm{el}} / \mathrm{t}_{\text {Steel }}\right]$
}




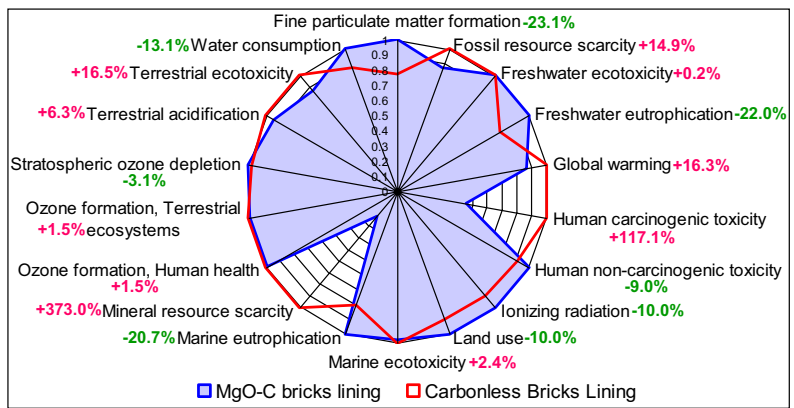

(a)

Fig. 5 Radar charts of the overall values of the impact categories (ReCiPe 2016-version 1.1, midpoint $\mathrm{H}$ ) as relative values of the reference $\mathrm{MgO}-\mathrm{C}$ bricks lining and of the carbonless bricks lining

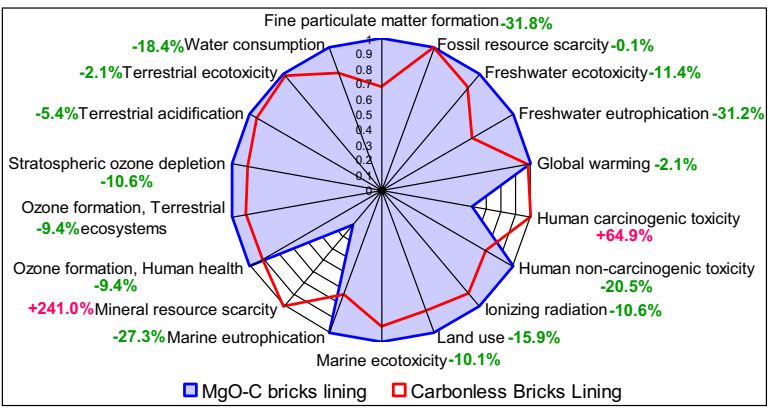

(b)

(F.U. $=1$ tonne of steel): $\mathbf{a}$ in scenario (a) with $N N H=40$ heats; $\mathbf{b}$ in scenario (b) with $N N H=60$ heats

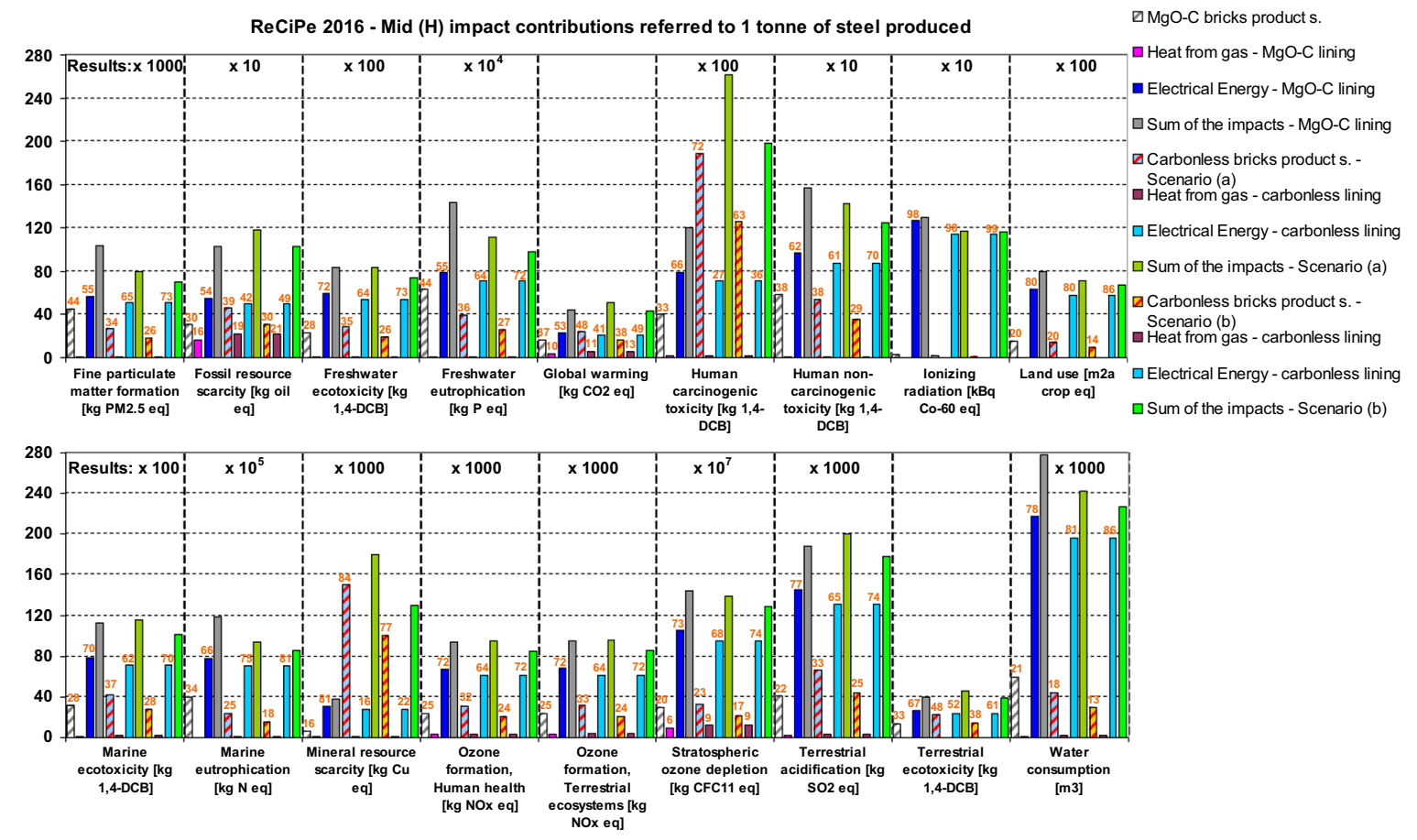

Fig. 6 Single contributions to the impact categories (ReCiPe 2016version 1.1 , midpoint $\mathrm{H}$ ) and their sums in the three cases $\mathrm{MgO}-\mathrm{C}$ lining, carbonless lining-scenario (a) and carbonless lining-sce- nario (b) (F.U. = 1 tonne of steel). The upper labels indicate the integer rounded percentages relative to the respective sums (values lower than $5 \%$ not shown)

eutrophication" (-22\%), "Marine eutrophication" (-21\%) and "Water consumption" $(-13 \%)$. In scenario (b), there are no further worsened impact categories besides the two already cited, while benefits exist for the remaining; the major reductions are found for: "Fine particulate matter formation" (-32\%), "Freshwater eutrophication" $(-31 \%)$, "Marine eutrophication" (-27\%) and "Water consumption" $(-18 \%)$. 
In Fig. 6 the three single contributions from the bricks' product systems, from gas and from electricity in the reference case and in the two scenarios are reported (as above mentioned, no differences exist between the two scenarios regarding natural gas and electricity impacts). As observable, in all the cases and for almost all the impact categories (except for "Global warming" in scenario (a) and for " Human carcinogenic toxicity" and "Mineral resource scarcity" in both scenarios (a) and (b)), the principal contribution comes from the electrical energy consumption, followed by the contribution from the brick product system, whereas the contribution from gas burning remains always marginal. These results underline the importance of the verification of the hypothesis regarding the foreseen reduction of electricity consumption (assumed $90 \%$ the current deduced value) with the carbonless bricks lining.

\section{Conclusion}

In the present paper, preliminarily, the boundaries and the assumptions of a cradle-to-gate LCA have been illustrated, finalized at the ecological comparison between the product systems of the currently used traditional $\mathrm{MgO}-\mathrm{C}$ refractory bricks (considering a reference recipe) and the more innovative "carbonless" ones, still under experimentation, in the context of the European research project "LeanStory." This evaluation, essential part of the project, has been carried out with data partly provided by the refractory brick manufacturer (recipes and suppliers' locations) and partly drawn from literature sources, considering as the functional unit of the analysis one tonne of bricks. Successively, for the purpose of transposing the ecological impacts to the production of steel, the functional unit has been shifted to one tonne of steel and three impact contributions have been taken into account: the impacts arising from the provision of the proper refractory bricks for the ladle lining, the impacts due to the consumption of natural gas for ladle pre-heating and heating after weekly maintenance stops (involving considerations and assumptions on the operational procedures in place at the workshop) and the impacts due to the consumption of electrical energy at each heat. As already pointed out, for the carbonless bricks lining, forecast assumptions regarding the operational performance of the ladle are employed, because of the lack of data drawn from full-scale industrial experimentations. The LCIA phase has been led by means of the methodology ReCiPe 2016 version 1.1 at the Midpoint impact categories and adopting the Hierarchist perspective.

The results of the comparison between the two brick product systems are reported in "Supplementary Appendix" and are useful in providing indications about the major ecological problems arising from the use of this more innovative type of refractory bricks. They strongly suggest the implementation of closed-loop recycling techniques also for this kind of spent refractories, finalized at recovering aluminum and reducing its consumption, according to practices already in place for the traditional $\mathrm{MgO}-\mathrm{C}$ refractories, as illustrated by Muñoz et al. (2020). However, on a more comprehensive basis, in the context of the applications in the steel industry, it is more important to focus the attention on the production of steel and in particular both on the specific consumption of refractory and on the differences arising from the operative procedures of the ladle.

When considering the total impact contributions, including also the impacts due to the consumption of natural gas for ladle pre-heating and heating after maintenance stops and to the consumption of electrical energy by the ladle at each heat, the worsened impacts observed in Fig. 3 are greatly smoothed. In fact, observing Fig. 5, it is evident how the ecological performances are strongly dependent on the foreseen average number of heats of the ladle lining life. In particular, in scenario (b) (with $N N H=60$ heats), only the two impact categories "Human carcinogenic toxicity" and "Mineral resource scarcity" show worsened results. Furthermore, observing the bar charts of the single contributions to the impacts in Fig. 6, it is worth noticing that for almost all the impact categories the dominant contributor is represented by the electrical energy consumption, followed by the contribution from the brick product systems, whereas the contribution from gas burning remains always marginal. More in detail, considering the three impact categories for which the contribution from the brick product systems attain the higher percentages, it is possible to find for "Mineral resource scarcity" $84 \%$ and $77 \%$ in the two scenarios (a) and (b), respectively; for "Human carcinogenic toxicity," $72 \%$ and $63 \%$, respectively; for "Global warming," $48 \%$ in scenario (a) only (38\% in scenario (b), but the contribution $49 \%$ from the electrical energy consumption is higher). As regards the share of the impacts due to the electrical energy consumption, considering the $\mathrm{MgO}-\mathrm{C}$ lining, it ranges from $54 \%$ for "Global warming" to $98 \%$ for "Ionizing radiation"; in the case of carbonless lining, it ranges from $16 \%$ (in scenario a) or $22 \%$ (in scenario b) for "Mineral resource scarcity" to $98 \%$ or $99 \%$ for "Ionizing radiation." The impact contribution share due to gas burning for heating purposes attains the maximum values for the category "Fossil resource scarcity" in all the three cases, being 16\% with the $\mathrm{MgO}-\mathrm{C}$ lining, $19 \%$ with the carbonless lining in scenario (a) and $21 \%$ in scenario (b).

In brief, the obtained results are strongly influenced by three major issues: (1) the reliability of data regarding the electrical consumption at each heat for the reference case (provided by the industrial partner); (2) the verification of the hypothesis regarding the foreseen reduction of electricity consumption (assumed 90\% the value of the reference case), 
thanks to the lower thermal conductivity of the carbonless bricks lining; (3) the validity of the assumed figures for the specific refractory consumption, deriving from the ladle lifetime in terms of average number of heats and possible only through the adherence to carefully controlled operational procedures.

It is important to underline that the performed cradleto-gate comparative LCAs between the two brick product systems (and the successive impact shifting to the steel production by means of the specific consumption) does not include the end-of-life phase of the spent refractories. However, at this regard, two aspects must be underlined. In the first place, according to Muñoz et al. (2020), actually, on a global base in the majority of industrial cases, the spent material is not recycled but treated as waste and disposed in landfills (although large differences could exist from country to country). Therefore this practice would just add further impact contributions of similar magnitude in both the cases of ladle lining materials and would not alter significantly the found comparative results. In the second place, in the calculations, the incidence of the impacts from end-of-life treatments should be referred to around half the original input mass of refractory material, since, according to a worldwide mass balance of refractories (Odreitz 2016), it is estimated that around $49 \%$ of the input mass is dissolved into the slag, while the major remaining part (36\%) is disposed in landfills. The first datum is also coherent with local figures in a Spanish steel works (Muñoz et al. 2020), in which the spent refractory percentage is around 54\% (6000 t / 11,000 t).

Future directions of the work encompass the comparison evaluation considering also the end-of-life phase of the refractories and, in particular, the recycling and re-use possibilities, as for example illustrated by Muñoz et al. (2020). Exemplary working technologies have been refined in the context of the European research project "Refrasort" (Connemann et al. 2016; Horckmans et al. 2016; Horckmans et al. 2019) and could be adapted for this innovative kind of refractory bricks, once proven its effective suitability in place of the currently used bricks. For a scientifically founded LCA from cradle-to-cradle, employing closedloop recycling practices enabling the re-use for the same purpose, the availability of reliable industrial data regarding the associated energy consumption and the quality of the obtained materials suitable for re-use (with reliable re-use percentages) plays a fundamental role. The inherent technological difficulties of implementing industrially feasible practices are well illustrated in Horckmans et al. 2019. In synthesis, they consist of: the appropriate sorting with acceptable purity levels of the fractions obtained after crushing, the need of a strict cooperation between refractory producers and recyclers to develop new formulations based on recycled materials, the creation of a long-term adequate and stable supply feed of high-quality secondary raw materials. These difficulties are exemplified in the case illustrated by Muñoz et al. (2020), where the quotas of the total spent $\mathrm{MgO}-\mathrm{C}$ bricks from EAF and ladles result split up as around 6\% only for re-use as secondary bricks (in prewall applications, emergency ladles, steel work pavements and similar uses), around $32 \%$ as secondary raw material (secondary magnesia, as DBM and FM), the remaining majority $(62 \%)$ as wastes directed to landfill. Also the economical viability of envisaged "closed-loop" solutions should be assessed, because, on the one hand, the perceived lower quality of the recycled materials compared to the virgin materials implies the willingness, from the refractory producers, of accepting higher risks only in return for cheaper costs (as far as the market price of many raw materials remains quite low). On the other hand, the low waste disposal costs (even in landfills) of relatively small amounts (per factory) of refractory wastes further limit the implementation of recycling solutions. It is reasonable to envisage that the industrial interest for recycling and re-use will receive an impulse under legislation constraints specifically conceived for limiting the use of natural resources and, in a long-term perspective, because of rising raw materials market prices and shortages. European industry and policy makers are aware of the potential weakness represented by the manifest dependence on resource imports, as already recognized in 2008 by the European Commission's "Raw Materials Initiative" (Commission of the European Communities 2008), one of whose three pillars is the "Resource efficiency and supply of secondary raw materials through recycling." These goals can also be found in the so-called European Green Deal (Commission of the European Communities 2019), in which, in the context of the key action "Industrial strategy for a clean and circular economy," the creation of "a robust and integrated single market for secondary raw materials and by-products" is invoked, through the adoption of legal requirements, setting mandatory recycled contents. The consequences of these future political initiatives and legal bindings will generate inevitably a fall-out also on the research sector for tuning innovative technologies at the service of refractory manufacturers and recycling industries.

Supplementary Information The online version contains supplementary material available at https://doi.org/10.1007/s13762-021-03553-2.

Acknowledgements The author acknowledges all the partners involved in the "LeanStory" project for their support to this research and in particular Roberto Caballero (R\&D manager at Insertec Refractory Solutions S.L.U.) and Asier Arteaga (senior researcher at Sidenor I+D) for the provision of personal communications and data.

Funding Open access funding provided by Politecnico di Bari within the CRUI-CARE Agreement. This research was funded by the EU 
under the Research Funds for Coal and Steel (RFCS), through the grant number RFSR-CT-2015-00005 ("LeanStory") funding.

\section{Declarations}

Conflict of interest The author declares no conflicts of interest. The funding sponsors had no role in the design of the study; in the collection, analyses or interpretation of data; in the writing of the manuscript or in the decision to publish the results.

Open Access This article is licensed under a Creative Commons Attribution 4.0 International License, which permits use, sharing, adaptation, distribution and reproduction in any medium or format, as long as you give appropriate credit to the original author(s) and the source, provide a link to the Creative Commons licence, and indicate if changes were made. The images or other third party material in this article are included in the article's Creative Commons licence, unless indicated otherwise in a credit line to the material. If material is not included in the article's Creative Commons licence and your intended use is not permitted by statutory regulation or exceeds the permitted use, you will need to obtain permission directly from the copyright holder. To view a copy of this licence, visit http://creativecommons.org/licenses/by/4.0/.

\section{References}

An J, Li Y, Middleton RS (2018) Reducing energy consumption and carbon emissions of magnesia refractory products: a life-cycle perspective. J Clean Prod 182:363-371. https://doi.org/10.1016/j. jclepro.2018.01.266

Arteaga AA, Ciriza J, Tonelli M, Martini U, Miceli P, Palm B, Aguglia $C$ (2014) Enhanced steel ladle life by improving the resistance of lining to thermal, thermomechanical and thermochemical alteration (Ladlife) - Final report for Grant Agreement RFSRCT-2009-00003 - European Commission Research Fund for Coal and Steel, Directorate-General for Research and Innovation. Publications Office of the European Union, Luxembourg. https://op. europa.eu/it/publication-detail/-/publication/fa07c10d-5325-4d2fb024-0c59bc5fb8f0. Accessed 26 July 2021

Boenzi F, Ordieres-Meré J, Iavagnilio R (2019) Life cycle assessment comparison of two refractory brick product systems for ladle lining in secondary steelmaking. Sustainability 11(5):1295. https:// doi.org/10.3390/su11051295

Braulio MAL, Rigaud M, Buhr A, Parr C, Pandolfelli VC (2011) Spinel-containing alumina-based refractory castables. Ceram Int 37(6):1705-1724. https://doi.org/10.1016/j.ceramint.2011.03.049

Buhr A (1999) Refractories for steel secondary metallurgy. CN-Refractories, vol 6, no 3, pp 19-30. http://almatis-umbraco.azurewebsi tes.net/media/3995/refractories_steel_secondary_metallurgy_ 1999.pdf. Accessed 26 July 2021

Buhr A, Bruckhausen R, Fahndrich R (2016) The steel industry in Germany - trends in clean steel technology and refractory engineering. Refractories WORLDFORUM, vol 8, no 1, pp 57-63. https:// www.refractories-worldforum.com/magazine/archive. Accessed 26 July 2021

Canikoğlu N, Toplan HO (2016) Production of magnesia-rich magnesium aluminate Spinel. Proceedings of the IMMC 2016 - 18th international metallurgy \& materials congress, Istanbul, Turkey, 29 Sept. - 1 Oct. 2016. UCTEA Chamber of Metallurgical \& Materials Engineers: Ankara, Turkey. http://www1.metalurji.org. tr/immc2016/188.pdf. Accessed 26 July 2021

Cappel J (2007) The link between refractories, slag, and steel in ferrous metallurgy. RHI Bulletin, vol 1, no 2007, pp 61-69. https://www.
cappel-consult.com/fileadmin/user_upload/29de_Refractories_ Metallurgy_METEC_2007_final.pdf. Accessed 26 July 2021

CEN - European Committee for Standardization (2006) EN ISO 14044:2006 Environmental management - Life cycle assessment - Requirements and guidelines (ISO 14044:2006)

Commission of the European Communities (2008) Communication from the Commission to the European Parliament and the Council - The raw materials initiative: meeting our critical needs for growth and jobs in Europe. Brussels. https://eur-lex.europa. eu/legal-content/EN/ALL/?uri=CELEX\%3A52008DC0699. Accessed 26 July 2021

Commission of the European Communities (2019) Communication from the Commission to the European Parliament, the European Council, the Council, the European Economic and Social Committee and the Committee of the Regions - The European Green Deal. Brussels. https://ec.europa.eu/info/sites/info/files/europeangreen-deal-communication_en.pdf. Accessed 26 July 2021

Connemann S, Fricke-Begemann C, Horckmans L, Ducastel A, Bouillot F, Knapp H, Makowe J, Stark A (2016) Automated LIBSbased classification for spent refractories from the steel industry for high-value recycling. In: Proceedings of the $7^{\text {th }}$ Sensor-Based Sorting \& Control 2016 (SBSC) Conference, Aachen, Germany, 23-24 February 2016. pp 119-127

Domínguez MI, Romero-Sarria F, Centeno MA, Odriozola JA (2010) Physicochemical characterization and use of wastes from stainless steel mill. Environ Prog Sustain Energy 29(4):471-480. https:// doi.org/10.1002/ep.10435

Dones R, Bauer C, Bolliger R, Burger B, Faist Emmenegger M, Frischknecht R, Heck T, Jungbluth N, Röder A, Tuchschmid M (2007) Life cycle inventories of energy systems: results for current systems in Switzerland and other UCTE Countries, ecoinvent report No. 5. Paul Scherrer Institut Villigen, Swiss Centre for Life Cycle Inventories, Dübendorf, Switzerland. http://ecolo.org/ documents/documents_in_english/Life-cycle-analysis-PSI-05.pdf. Accessed 26 July 2021

Dutta SK, Chokshi YB (2020) Secondary Steelmaking. In: Basic Concepts of Iron and Steel Making. Springer, Singapore, pp. 497-536. https://doi.org/10.1007/978-981-15-2437-0_17. https://link.sprin ger.com/chapter/10.1007\%2F978-981-15-2437-0_17\#citeas

Ebner C, Skala K, Rechberger L, Neubauer B (2017) Avoidance of hazardous substances via low emission $\mathrm{MgO}-\mathrm{C}$ technology shown with the example of a ladle lining refractory. RHI bulletin - The Journal of Refractory Innovations - Steel and Industrial Edition Bulletin 1 (2017):22-27. https://www.rhimagnesita.com/wp-conte nt/uploads/2017/12/Bulletin-2017-1-171130-Hyperlink_mon.pdf. Accessed 26 July 2020

Erzkontor GmbH \& Co. site (2021) Product Information - SinteredMA-Spinel. https://www.erzkontor.com/en/products/industry/refra ctory-industry/sintered-ma-spinel.html. Accessed 26 July 2021

European Commission - Joint Research Center (JRC) (2007) Reference Document on Best Available Techniques in the Ceramic Manufacturing Industry. European Commission, Luxembourg. https://eippcb.jrc.ec.europa.eu/sites/default/files/2019-11/cer_ bref_0807.pdf. Accessed 26 July 2021

European Commission - Joint Research Center (JRC). Remus R, Aguado Monsonet MA, Roudier S, Delgado Sancho L (2013) Best Available Techniques (BAT) Reference Document for Iron and Steel Production. Publications Office of the European Union, Luxembourg. http://publications.jrc.ec.europa.eu/repos itory/bitstream/JRC69967/lfna25521enn.pdf. Accessed 26 July 2021

Ewais EMM (2004) An outlook on metallurgy and refractory industry in Arab countries. In: Proceedings of the Tehran International Conference on Refractories, Tehran, Iran, 4-6 May 2004. pp $662-678$ 
Fang H, Smith JD, Peaslee KD (1999) Study of spent refractory waste recycling from metal manufacturers in Missouri. Resour Conserv Recy 25(2):111-124. https://doi.org/10.1016/S0921-3449(98) 00059-7

Funabiki K, Nakamura M, Tsuriya M (1981) Carbonization of phenolic resins. Jpn Thermosetting Plast Ind Assoc 2(4):220-235

Ghosh A, Chatterjee A (2008) Ironmaking and steelmaking - theory and practice. Prentice-Hall of India, New Delhi, India, pp 362-396

Glaser B, Gornerup M, Sichen D (2011) Thermal modelling of the ladle preheating process. Steel Res Int 82(12):1425-1434

Horckmans L, Knapp H, Dierckx P, Nielsen P, Bouillot F, FrickeBegemann C, Makowe J, Stark A, Ducastel A (2016) Refrasort: Automated sorting of refractory waste for high value recycling. In: Proceedings of the 7th Sensor-Based Sorting \& Control 2016 (SBSC) Conference, Aachen, Germany, 23-24 February 2016. http://publications.rwth-aachen.de/record/668852/files/668852. pdf. Accessed 26 July 2021

Horckmans L, Nielsen P, Dierckx P, Ducastel A (2019) Recycling of refractory bricks used in basic steelmaking: a review. Resour Conserv Recy 140:297-304. https://doi.org/10.1016/j.resconrec. 2018.09.025

Huarachi DAR, Gonçalves G, de Francisco AC, Giovanetti Canteri MH, Moro Piekarski C (2020) Life cycle assessment of traditional and alternative bricks: a review. Environ Impact Assess Rev 80:106335. https://doi.org/10.1016/j.eiar.2019.106335

Hubble DH (1998) Chapter 3 - Steel Plant Refractories. In: The Making, Shaping and Treating of Steel, 11th edition. Fruehan, R. J., Ed.. The AISE Steel Foundation, Pittsburgh, PA (U.S.A.) Steelmaking and Refining Volume, pp 159-226. ISBN: 0-930767-02-0

Huijbregts MAJ, Steinmann ZJN, Elshout PMF, Stam G, Verones F, Vieira M, Zijp M, Hollander A, van Zelm R (2017a) ReCiPe2016: a harmonised life cycle impact assessment method at midpoint and endpoint level. Int J Life Cycle Assess 22:138-147. https://doi. org/10.1007/s11367-016-1246-y

Huijbregts MAJ, Steinmann ZJN, Elshout PMF, Stam G, Verones F, Vieira MDM, Hollander A, Zijp M, van Zelm R (2017b) ReCiPe 2016 v1.1 - A harmonized life cycle impact assessment method at midpoint and endpoint level - Report I: Characterization - RIVM Report 2016-0104a. RIVM (National Institute for Public Health and the Environment), Bilthoven, The Netherlands. https://www. rivm.nl/sites/default/files/2018-11/Report\%20ReCiPe_Update_ 20171002_0.pdf. Accessed 26 July 2021

Ioana A, Constantin N, Paunescu L, Dobrescu C, Surugiu G, Polifroni M (2017) Contribution to improving the durability of the refractory lining of the steel ladles. U.P.B. Sci. Bull. Series B 79(1):201-220. https://www.scientificbulletin.upb.ro/rev_docs_ arhiva/fulla67_481631.pdf. Accessed 26 July 2021

Irie S, Rappolt J (2010) Chapter 19 - Phenolic resin for refractories. In: Pilato L (ed) Phenolic resins: a century of progress. Springer, Berlin Heidelberg, Germany, pp 503-516 (ISBN 978-3-642-04713-8 e-ISBN 978-3-642-04714-5)

Jameson CW (2019) Chapter 7 - Polycyclic aromatic hydrocarbons and associated occupational exposures. In: Baan RA, Stewart BW, Straif K (eds) Tumour site concordance and mechanisms of carcinogenesis - IARC Scientific Publication No. 165. International Agency for Research on Cancer, 69372 Lyon Cedex 08, France, pp 59-63. http://publications.iarc.fr/_publications/media/downl oad/5133/efed9a637bde4f0f23c495933b712a0e249d3457.pdf. Accessed 26 July 2021

Keralit - Magnesium-aluminate spinel (2016). http://www.keralit.com/ eng/raw_materials/aluminium_spinel. Accessed 26 July 2021

Kirschen M, de Oliveira SP, Shikhmetov E, Höck M (2012) Customerspecific analysis of steelmaking slags to provide process and refractory lining lifetime improvements in steel treatment ladles and eafs. RHI Bull 1:20-25

Koros PJ (2003) Dusts, scale, slags, sludges... not wastes, but sources of profit. Metall Mater Trans B 34B(6):769-779. https://doi.org/ 10.1007/s11663-003-0083-0

Kriechbaum GW, Schäfer E, Munding S, Gnauck V, Cross N (1992) New sinter spinels for castables in steel applications. Almatis Technical papers. http://almatis.com/media/i3afs1ue/new-sinterspinels-for-castables-in-steel-applications.pdf. Accessed 26 July 2021

Kuznetsov AV, Lozin GA, Derevyanchenko IV, Konyukhov VV (2003) Optimizing the conditions for pre-start heating of the refractory lining of steel-teeming ladles. Refract Ind Ceram 44:22-26. https://doi.org/10.1023/A:1023959510287

Li J, Zhang Y, Shao S, Zhang S, Ma S (2016) Application of cleaner production in a Chinese magnesia refractory material plant. J Clean Prod 113:1015-1023. https://doi.org/10.1016/j.jclepro. 2015.11.040

Moch W, Gregor MA, Adler W, Bende W, Burkat C, de Fries U, Mees H, Wiedemeier F-J, De Angelis V, De Paolis G, Marconi U, Celia E, Falcioni F, Martini U, Paciello M, Tonelli M, Muñoz J-L (2008) Investigations and measures to reduce emissions and energy consumption during the preheating of steel ladles - Final report for Contract No RFSR-CT-2003-00008 - European Commission Research Fund for Coal and Steel, Directorate-General for Research, Office for Official Publications of the European Communities, Luxembourg. https://op.europa.eu/it/publicationdetail/-/publication/74b14123-0e3f-4c8c-b805-15ce4c85c8b4. Accessed 26 July 2021

Muñoz I, Soto A, Maza D, Bayón F (2020) Life cycle assessment of refractory waste management in a Spanish steel works. Waste Manag 111:1-9. https://doi.org/10.1016/j.wasman.2020.05.023

Odreitz W (2016) Recycling refractories from an end user's viewpoint. Mineral Recycling Forum 2016, Rotterdam, The Netherlands, $14-15$

openLCA - the Life Cycle and Sustainability Modeling Suite (2021). http://www.openlca.org/openlca. Accessed 26 July 2021

Ozkan A, Günkaya Z, Tok G, Karacasulu L, Metesoy M, Banar M, Kara A (2016) Life cycle assessment and life cycle cost analysis of magnesia spinel brick production. Sustainability 8(7):662. https:// doi.org/10.3390/su8070662

Pissenberger E, Reisinger P, Tiekink W, Winkhold A, Fandrich R, Petry S, Ender A, Müller KT, Bolender T, Becker R, Jaccobi H (2009) Optimisation and evaluation of different secondary metallurgy routes to achieve high-quality strip steel - Final report for Contract No 7210-PR/332. European Commission Technical steel research, Directorate-General for Research, Office for Official Publications of the European Communities, Luxembourg. https:// op.europa.eu/it/publication-detail/-/publication/e59c1131-cdb4434a-b12e-a9138821ebac. Accessed 26 July 2021

Santos MF et al (2018) Enhanced numerical tool to evaluate steel ladle thermal losses. Ceram Int 44(11):12831-12840. https://doi.org/10. 1016/j.ceramint.2018.04.092

Santos MF et al. (2020) C-1Free refractory for reducing the steel ladle energy consumption: numerical analysis and In-situ measurements. Refractories WORLDFORUM 12(3):36-41. https:// www.refractories-worldforum.com/issuebrowser/rwf_2020_3/ flipviewerxpress.html. Accessed 26 July 2021

Schmidtmeier D, Büchel G, Buhr A (2009) Magnesium aluminate spinel raw materials for high performance refractories for steel ladles. Mater Ceram Ceram Mater 61(4):223-227

Seeger M, Otto W, Flick W, Bickelhaupt F, Akkerman OS (2011) Magnesium Compounds. In: Ullmann's Encyclopedia of Industrial Chemistry. Wiley-VCH Verlag GmbH \& Co. KGaA. https://doi. 
org/10.1002/14356007.a15_595.pub2. https://onlinelibrary.wiley. com/doi/book/10.1002/14356007

Sheila D (1993) Thermal analysis studies on the decomposition of magnesite. Int J Miner Process 37:73-88. https://doi.org/10.1016/ 0301-7516(93)90006-V

Smith JD, Fang H, Peaslee KD (1999) Characterization and recycling of spent refractory wastes from metal manufacturers in Missouri. Resour Conserv Recy 25(2):151-169. https://doi.org/10.1016/ S0921-3449(98)00050-0

Svantesson J, Glaser B, Ersson M, White J, Imris M, Jönsson P (2020) Study of dynamic refractory wear by slags containing very high $\mathrm{FeO}$ contents under steelmaking conditions. Ironmak Steelmak. https://doi.org/10.1080/03019233.2020.1827672

The ecoinvent Database (2017). https://urldefense.proofpoint.com/v2/ $\mathrm{url}$ ? $\mathrm{u}=\mathrm{https}-3 \mathrm{~A} \_\mathrm{www}$. ecoinvent.org_database_older-2Dversions_ ecoinvent-2D34_ecoinvent-2D34.html\&d=DwIFAw\&c=vh6Fg FnduejNhPPD0f1_yRaSfZy8CWbWnIf4XJhSqx8\&r=7GjDei_ PxQva2JNOfHbJQKIolTpKkGdW_4o9-CecCzX9fDPu7SrgsodpY
CPByYz6\&m=9bLgA77pXcbxdpymrStoFVhdf-gexH7pBMmx 6x9IqxU\&s=n3tgzZfKmiM7iFJ-WksfUPl-xMi0z3zv6rBqzZv trOw\&e=. Accessed 26 July 2021

Wang H, Sichen Du (2016) Improvement of resistance to slag penetration in magnesia-based refractory with colloidal alumina addition II by means of a proper particle size distribution of $\mathrm{MgO}$. Metall and Mater Trans B. https://doi.org/10.1007/s11663-016-0649-2

Wang H, Glaser B, Sichen Du (2015) Improvement of resistance of $\mathrm{MgO}$-based refractory to slag penetration by in situ spinel formation. Metall Mater Trans B. https://doi.org/10.1007/ s11663-014-0277-7

Wang H, Caballero R, Sichen D (2017) Dissolution of MgO based refractories in $\mathrm{CaO}-\mathrm{Al} 2 \mathrm{O} 3-\mathrm{MgO}-\mathrm{SiO} 2$ slag. J Eur Ceram Soc. https://doi.org/10.1016/j.jeurceramsoc.2017.09.030

Zhang S, Lee WE (2004) Spinel-containing refractories. In: Schacht CA (ed) Refractories Handbook, 1st edn. Marcel Dekker Inc., New York U.S.A, pp 81-139 